\title{
The long noncoding RNA HOTAIRM1 controlled by AML1 enhances glucocorticoid resistance by activating RHOA/ROCK1 pathway through suppressing ARHGAP18
}

\author{
Liang Liang ${ }^{1,2}$, Wenbin $\mathrm{Gu}^{1,2}$, Meng $\mathrm{Li}^{1,2}$, Ran Gao ${ }^{1,2}$, Xin Zhang ${ }^{1,2}$, Chongye Guo ${ }^{1,2}$ and Shuangli Mi (iD) \\ (c) The Author(s) 2021
}

Acquired resistance to glucocorticoids (GCs) is an obstacle to the effective treatment of leukemia, but the molecular mechanisms of steroid insensitivity have not been fully elucidated. In this study, we established an acquired GC-resistant leukemia cell model and found a long noncoding RNA, HOTAIRM1, was overexpressed in the resistant cells by transcriptional profiling, and was higher expressed in patients with poor prognosis. The whole-genome-binding sites of HOTAIRM1 were determined by ChIRP-seq (chromatin isolation by RNA purification combined with sequencing) analysis. Further study determined that HOTAIRM1 bound to the transcriptional inhibitory region of ARHGAP18 and repressed the expression of ARHGAP18, which led to the increase of RHOA/ ROCK1 signaling pathway and promoted GC resistance through antiapoptosis of leukemia cells. The inhibition of ROCK1 in GCresistant cells could restore GCs responsiveness. In addition, HOTAIRM1 could also act as a protein sequester to prevent transcription factor AML1 (acute myeloid leukemia 1) from binding to the regulatory region of ARHGAP18 by interacting with AML1. At last, we also proved AML1 could directly activate the expression of HOTAIRM1 through binding to the promoter of HOTAIRM1, which enriched the knowledge on the regulation of IncRNAs. This study revealed epigenetic causes of glucocorticoid resistance from the perspective of IncRNA, and laid a foundation for the optimization of glucocorticoid-based leukemia treatment strategy in clinic.

Cell Death and Disease (2021)12:702; https://doi.org/10.1038/s41419-021-03982-4

\section{INTRODUCTION}

Glucocorticoids (GCs) are steroid hormones with antiinflammatory and immunosuppressive effects [1-4]. Synthetic glucocorticoid analogues, such as dexamethasone (Dex) and prednisolone, are usually used in combination with other chemotherapy drugs for the treatment of hematological malignancies because they can induce apoptosis of lymphocytic cells [5-8]. Unfortunately, glucocorticoid resistance is the main cause of treatment failure [9-11]. It can be induced by a variety of mechanisms [12, 13], which may be different in individuals [14]. For example, the decrease in corticosteroid responsiveness may be attributed to the decrease in number of GRs (glucocorticoid receptors) [15], the change in affinity of GRs ligands [16], the decrease in binding ability of GRs to DNA [17], or the increase in expression of inflammatory transcription factors (such as AP-1) competing for DNA binding [18]. Nevertheless, the understanding of $\mathrm{GC}$ resistance is still incomplete.

GCs induce apoptosis by activating intrinsic mitochondrial apoptosis pathway, which is regulated by pro- and antiapoptotic BCL2 family proteins [19]. Some signaling pathways are critical for GC-induced apoptosis [20,21], and GC resistance is often related to the defect of apoptosis machinery rather than GR [22, 23]. For example, BIM plays an essential role in Dex-induced apoptosis [24].
It was upregulated through p38-MAPK activation in acute lymphoblastic leukemia cells after dexamethasone treatment, which could be blocked by p38-MAPK inhibitor [25]. These facts implicate that the deficiency of apoptosis ability or upstream signal transduction pathways not only provide cancer cells with an intrinsic survival advantage, but also may lead to inherent resistance to chemotherapeutic drugs.

Recently, it has been found that long noncoding RNAs (IncRNAs) can regulate the sensitivity of tumor cells to drugs by participating in cell cycle, apoptosis, DNA damage repair, drug metabolism, and other pathways [26-28]. However, the study of IncRNA on glucocorticoid resistance is very rare. Currently, IncRNA GAS5 has been found to interact with GR [29] and enter the nucleus together, which blocks the binding of GR to GR binding element (GRE) by competing for GR, thus inhibiting the expression of GR target genes [30,31]. A study has shown that after treatment with methylprednisolone (MP) in vitro, the expression of endogenous GAS5 increased in drug-resistant peripheral blood mononuclear cells. The expression of GAS5 in MP poor responders was higher than that in MP good responders, which indicates that GAS5 may participate in GC resistance [32]. Another IncRNA that may be related to $G C$ resistance is SRA. SRA can interact with the nuclear receptor co-activator SRC-1, which is recruited by nuclear

\footnotetext{
${ }^{1}$ Key Laboratory of Genomic and Precision Medicine, Beijing Institute of Genomics, Chinese Academy of Sciences, China National Center for Bioinformation, Beijing, China. ${ }^{2}$ University of Chinese Academy of Sciences, Beijing, China. ${ }^{凶}$ email: mishl@big.ac.cn Edited by B. Rotblat
} 
A

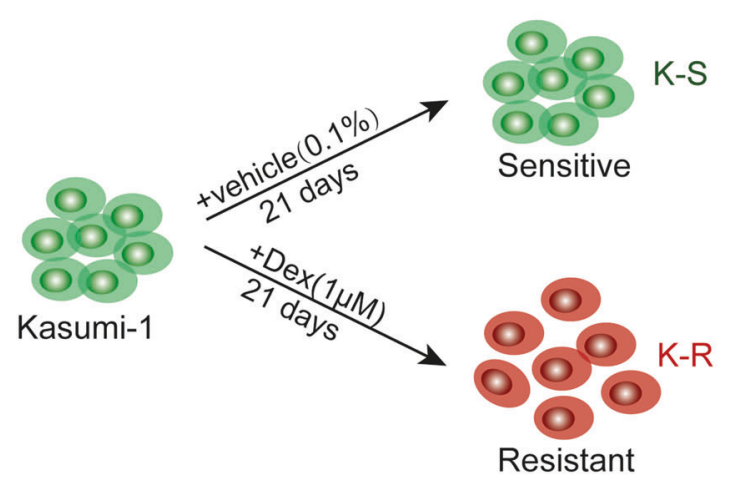

C

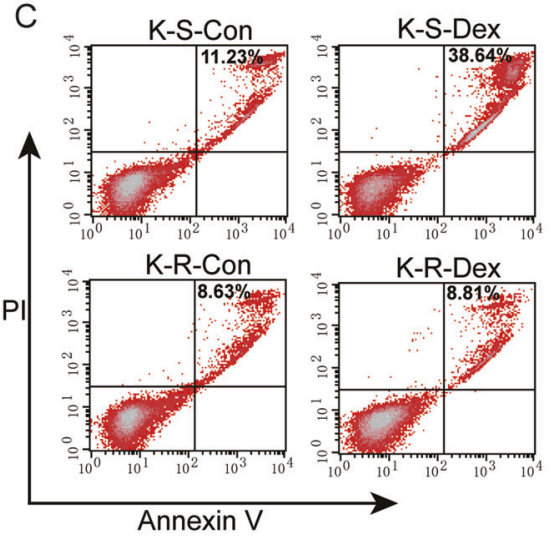

B

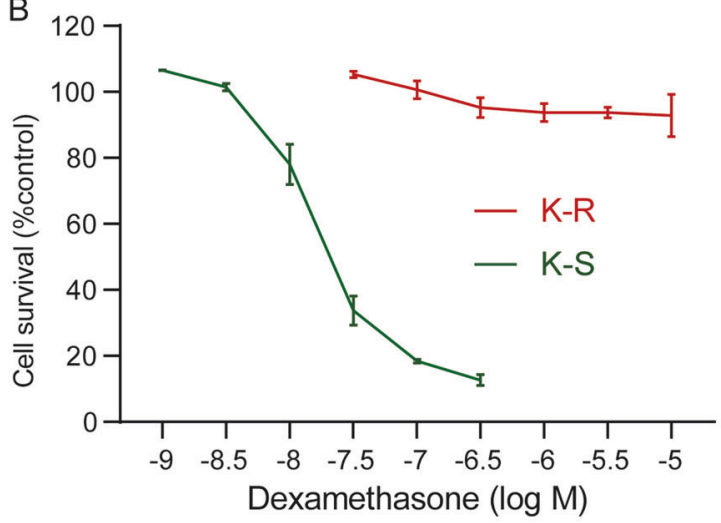

E

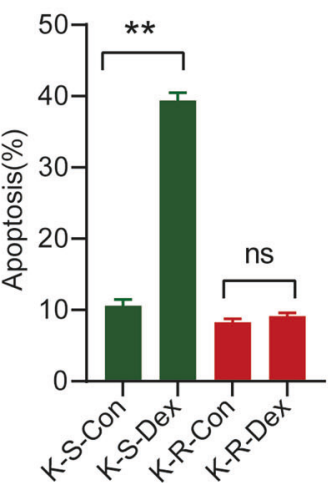

$\mathrm{F}$

\section{BCL2}

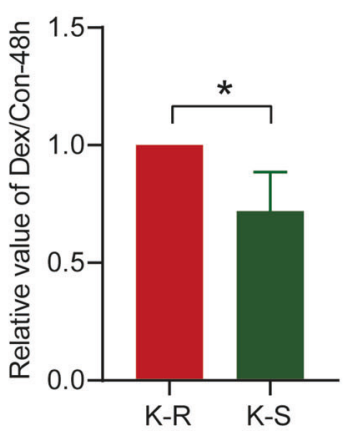

BCL2L11

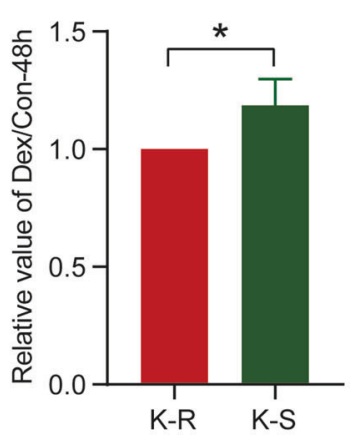

Fig. 1 Establishment and characterization of GC-resistant Kasumi-1 cells (K-R). A Schematic diagram of the experimental approach for the establishment of glucocorticoid-resistant cells in vitro. In continued presence of $1 \mu \mathrm{M}$ dexamethasone, the residual survival colonies of Kasumi-1 were isolated and iteratively passaged over 21 days. These colonies were designated as K-R. At the same time, the same operation was performed in the control group treated with the same concentration of vehicle, named K-S. B K-R and K-S cells were treated with various concentrations of dexamethasone for 4 days, and the cell viability was measured by MTS assay. C Flow cytometry analysis of Annexin V and PI in K-R and K-S cells. Both cells were treated with vehicle and $10 \mu \mathrm{M}$ dexamethasone for $48 \mathrm{~h}$ prior to staining. D Quantitative analysis of Annexin $\mathrm{V}+/ \mathrm{PI}+$ in flow cytometry. E Expression ratio of $\mathrm{BCL} 2$ in glucocorticoid group and control group after $48 \mathrm{~h}$ Dex treatment. $\mathbf{F}$ Expression ratio of $\mathrm{BCL2L11}$ in glucocorticoid group and control group after $48 \mathrm{~h}$ Dex treatment. Data information: Data were represented as mean \pm SD, $n=3$ (B, D-F). Difference between groups was assessed using Student's $t$-test: ${ }^{*} p<0.05,{ }^{* *} p<0.01,{ }^{* * *} p<0.001$, ns means no statistical significance.

receptors, including PR and GR [33]. In HeLa cells, the genes regulated by GR changed after SRA knockdown, which suggests that SRA may affect GR and then GC resistance [34]. Although IncRNAs GAS5 and SRA have been confirmed to interact with GR or be able to affect the regulation of GR target genes, it is unclear whether they can play a direct role in GC resistance.

The emergence of IncRNAs provides a new field for the study of $\mathrm{GC}$ resistance. It will help to understand the molecular mechanism of $\mathrm{GC}$ resistance comprehensively, lay the foundation for overcoming the GC resistance and improving the curative efficacy of glucocorticoid drugs.

\section{RESULTS}

\section{Establishment of glucocorticoid-resistant cells}

In order to study the possible causes of GC resistance, we adopted the strategy of inducing sensitive cells into resistant cells to minimize the impact of differences in genetic background between different cells. Kasumi-1, which is a GC-sensitive $t(8: 21)$ acute myeloid leukemia cell line [35], was transformed into GC-resistant cells after continuous exposure to $1 \mu \mathrm{M}$ dexamethasone ethanol solution for 21 days, and designated as Kasumi-1-dexamethasoneresistant cells (K-R). Meanwhile, the corresponding ethanol solvent treatment group was defined as Kasumi-1-dexamethasone-sensitive cells (K-S) (Fig. 1A). The drug sensitivity assay showed dexamethasone could inhibit K-S at low concentrations, while even high concentrations of dexamethasone could not inhibit the growth of $\mathrm{K}$ $R$ (Fig. 1B). K-R cells could maintain GC resistance after 25 days of culture in GC-withdrawn medium (Supplementary Fig. S1A), indicating that the established K-R have stable and long-lasting $\mathrm{GC}$ resistance. Morphologically, the distribution of $\mathrm{K}-\mathrm{R}$ in medium was more dispersed than that of K-S (Supplementary Fig. S1B), suggesting that it may have different characteristics between K-R and K-S. Compared with K-S, the apoptosis rate of K-R treated with GC for $48 \mathrm{~h}$ decreased remarkably (Fig. 1C, D). Gene expression detection showed that after $48 \mathrm{~h}$ of Dex stimulation, the change ratio of antiapoptotic gene $\mathrm{BCL} 2$ in $\mathrm{K}-\mathrm{R}$ was significantly higher than that of K-S (Fig. 1E), while the change ratio of proapoptotic gene BCL2L11 was significantly lower than that of K-S (Fig. 1F). These results further confirmed that K-R and K-S had significant differences in glucocorticoid resistance.

\section{HOTAIRM1 enhanced dexamethasone resistance by affecting} apoptosis

We first considered the known glucocorticoid resistance mechanisms in this model. There was no gene mutation and copy number 
A

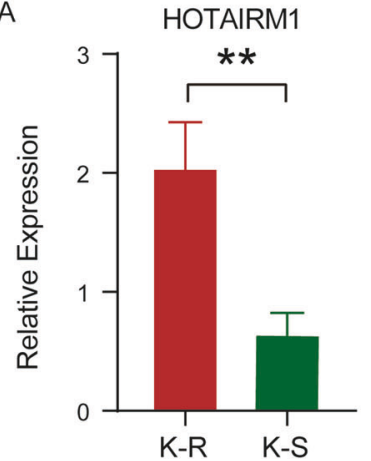

C

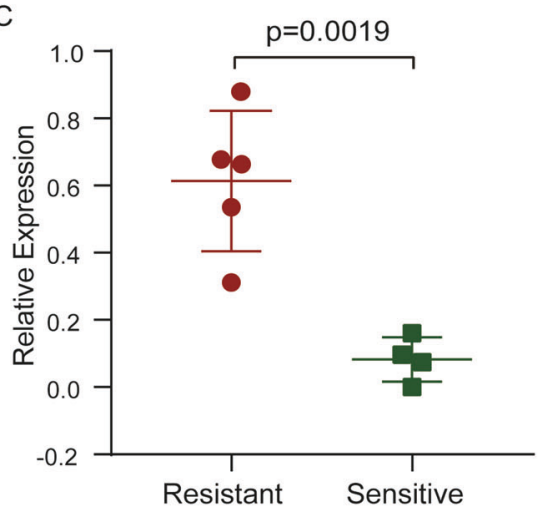

B

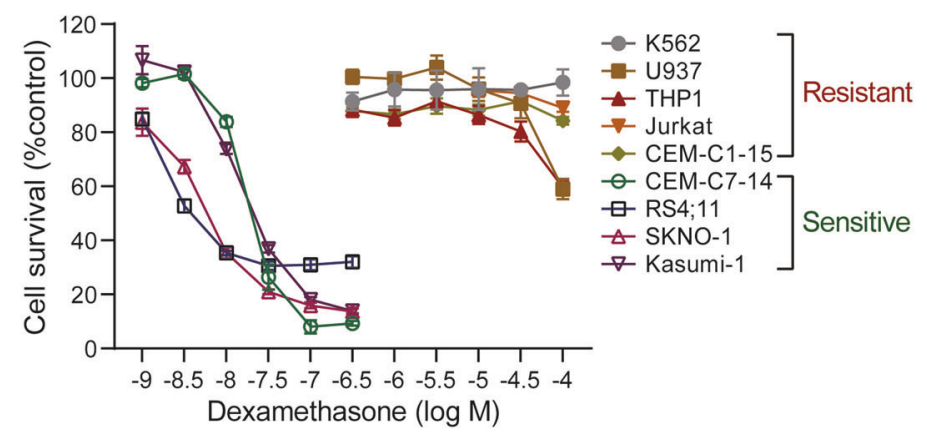

D

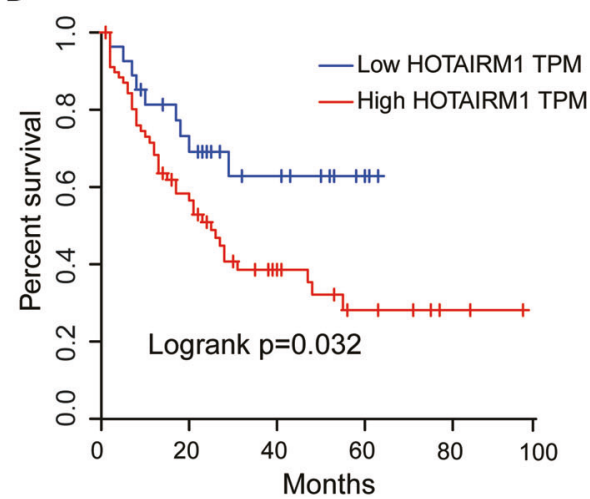

Fig. 2 High expression of HOTAIRM1 in GC-resistant leukemia cells. A The relative expression of HOTAIRM1 was measured in K-R and K-S using quantitative RT-PCR (qRT-PCR). ACTB was the reference gene. Data represent the mean \pm SD of three experiments, $n=3$. Difference between groups was assessed using Student's $t$-test: ${ }^{*} p<0.05,{ }^{* *} p<0.01,{ }^{* * *} p<0.001$, ns means no statistical significance. B Detection of GC sensitivity among leukemia cell lines (K562, U937, THP1, Jurkat, CEM-C1-15, CEM-C7-14, RS4;11, SKNO-1, Kasumi-1). Cells were treated with various concentrations of dexamethasone for 4 days, and the cell viability was determined by MTS assay. Based on the results, these cell lines were divided into two groups: resistant cells and sensitive cells. C Relative expression of HOTAIRM1 in corresponding cells with different responses (Resistant and Sensitive) to GCs. Difference between groups was assessed using Student's $t$-test $(p=0.0019)$. D Kaplan-Meier overall survival curve of AML patients according to HOTAIRM1 expression level from TCGA data, $P$-value of log-rank test is 0.032 .

change in GR in K-R cells. The expression level of GR protein had no significant difference between K-R and K-S (Fig. S2A, B).

Next, we detected the difference in gene expression between sensitive and resistant cells. Through transcriptome analysis, we found 844 genes upregulated and 301 genes downregulated in K$\mathrm{R}$ compared with K-S (Log2 Fold Change $>1$ or $<-1$, $P$-value $<$ 0.05) (Supplementary Table S1). Among the differentially expressed genes, IncRNAs accounted for a certain proportion. HOTAIRM1(HOXA transcript antisense RNA, myeloid-specific 1) was one of the significantly upregulated IncRNAs in K-R (Fig. 2A), which was located in the HOX gene cluster [36-39]. Then, we checked the expression of HOTAIRM1 in nine leukemia cells including K562, U937, THP1, Jurkat, CEM-C1-15, CEM-C7-14, RS4;11, SKNO-1, and Kasumi-1. According to the sensitivity to Dex determined by IC50 (the half-maximal inhibitory concentration) assay, these cell lines were divided into two groups: resistant cells and sensitive cells (Fig. 2B, Supplementary Table S2). We found that the expression of HOTAIRM1 in resistant cells was significantly higher than that in sensitive cells (Fig. 2C). The analysis of the AML data repository from TCGA (The Cancer Genome Atlas) [40] revealed that HOTAIRM1 expression was higher across AML samples than that in paired normal tissues (Supplementary Fig. S2C). Additionally, Kaplan-Meier survival analysis indicated that high expression of HOTAIRM1 in AML patients was associated with poor overall survival and recurrencefree survival (Fig. 2D). These findings led us to further explore the function of HOTAIRM1 in dexamethasone resistance.

We knocked down HOTAIRM1 in K-R (Supplementary Fig. S3A) and found the tolerance of cells to glucocorticoids was significantly reduced (Fig. 3A). At $48 \mathrm{~h}$ after GC treatment, K-R cells with HOTAIRM1 knockdown showed higher rate of apoptosis compared with control (Fig. 3B). The antiapoptosis gene BCL2 (Fig. 3C) and proapoptosis gene BCL2L11 (Fig. 3D) also changed accordingly. Meanwhile, cell viability was not affected by HOTAIRM1 knockdown without Dex treatment (Supplementary Fig. S3B), indicating that HOTAIRM1 did not affect cell growth in the absence of Dex treatment. On the contrary, overexpression of HOTAIRM1 in K-S and another GCsensitive cell line SKNO-1 could significantly enhance GC resistance (Fig. 3E, F).

Then we investigated the regulatory relationship between GR and HOTAIRM1. First, we used GR antibody to do ChIP-seq in $\mathrm{K}-\mathrm{R}$ and $\mathrm{K}-\mathrm{S}$, but did not find $\mathrm{GR}$ binding in regulator region of HOTAIRM1. Then we detected the protein expression levels after HOTAIRM1 knockdown, and did not observe significant effect on the expression of GR (Supplementary Fig. S3C). Moreover, most of the reported GR target genes were not affected by HOTAIRM1 knockdown (Supplementary Fig. S3D). The above results imply HOTAIRM1 may not affect GC resistance through $\mathrm{GR}$.

To understand the effect of genes regulated by HOTAIRM1 on dexamethasone sensitivity, we conducted transcriptome comparison analysis between K-R and K-R with HOTAIRM1 knockdown (K-R-KD). We obtained 110 differentially expressed genes (Log2 Fold Change $>1$ or $<-1, p<0.05$ ), among which 74 were upregulated and 36 were downregulated (Supplementary Fig. S3E, Supplementary Table S3). Further functional enrichment analysis showed that the differentially expressed genes were 


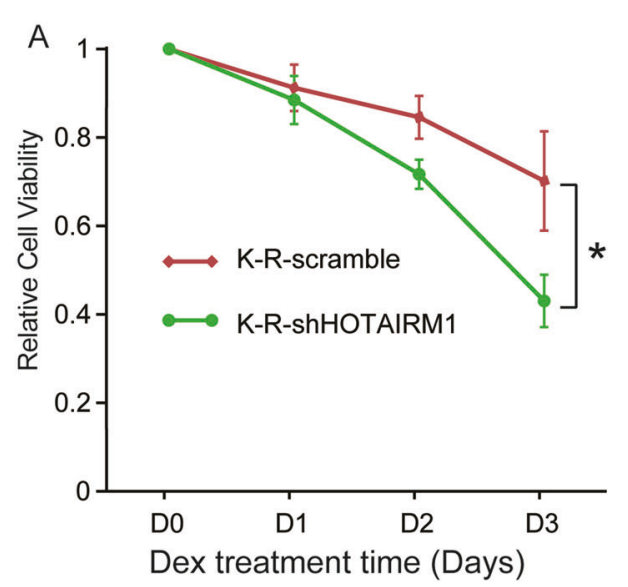

B

C

D
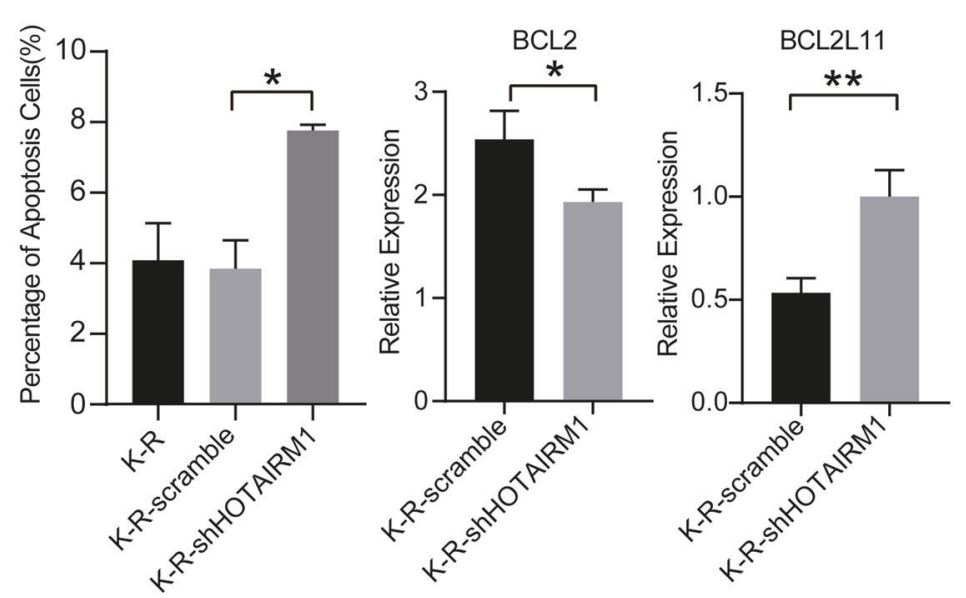

$\mathrm{E}$

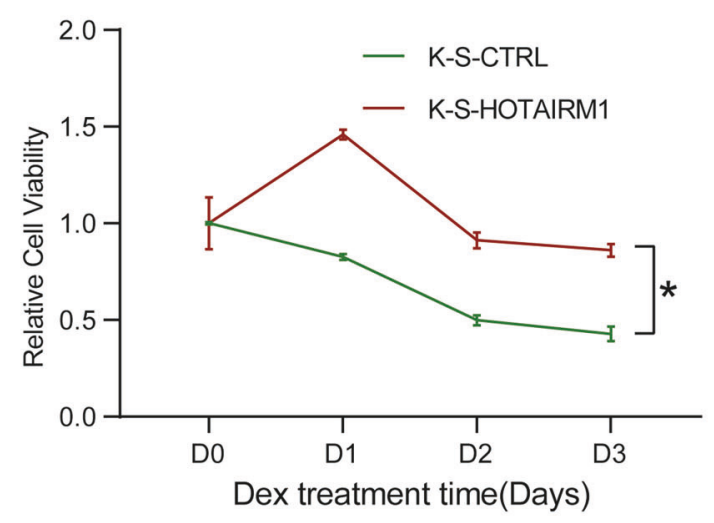

$\mathrm{F}$

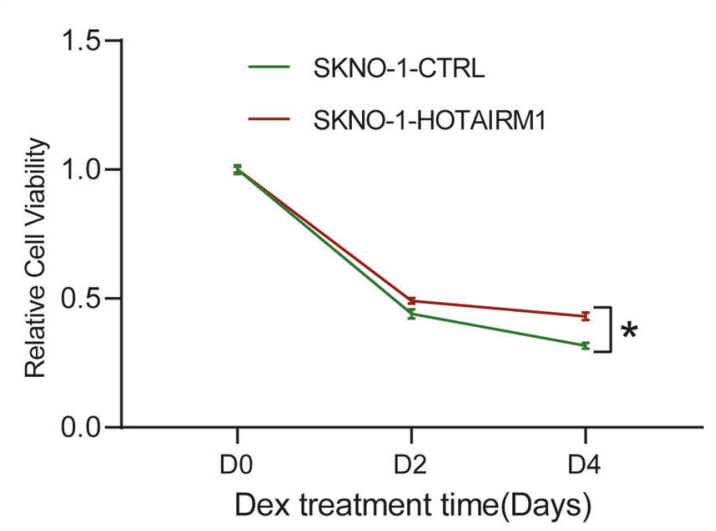

G

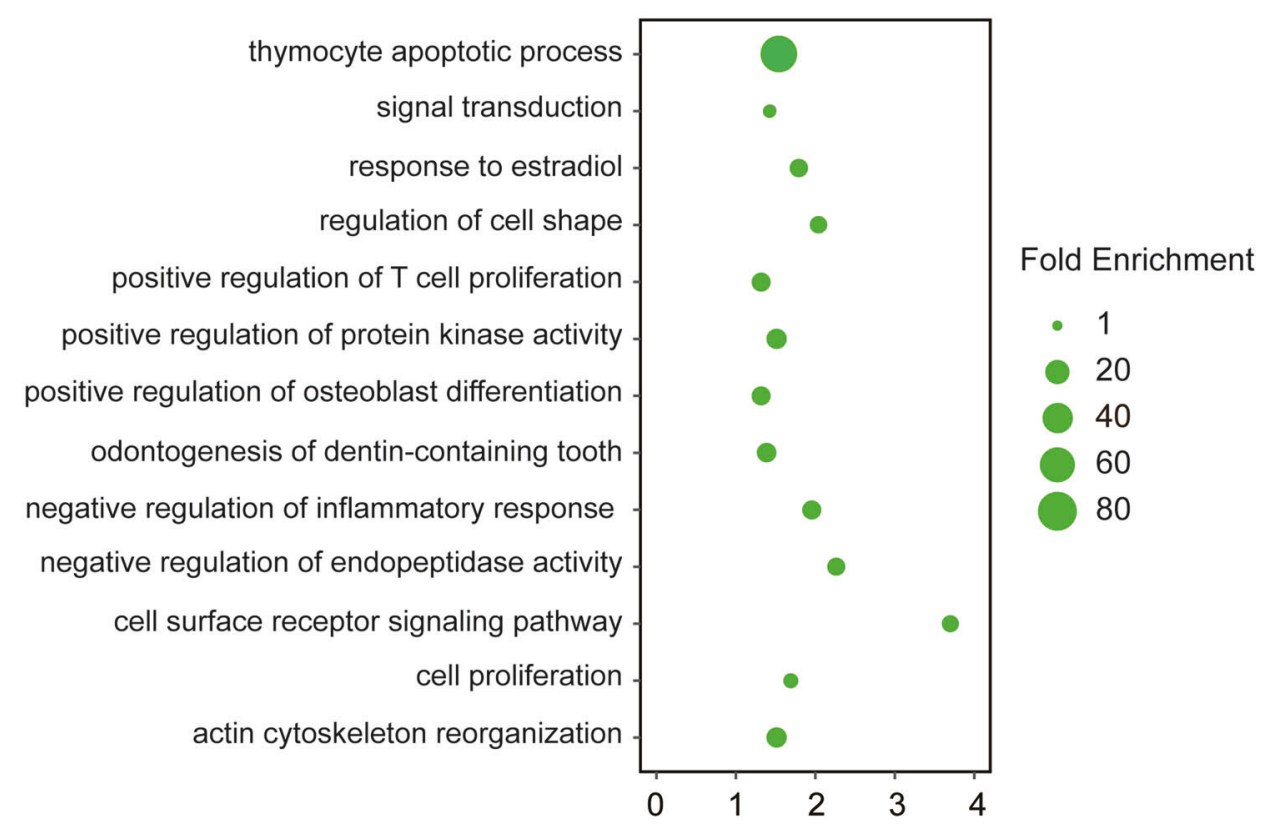

significantly enriched in the pathway of thymocytes apoptotic process (Fig. 3G). These results suggested that HOTAIRM1 regulated cell resistance to glucocorticoids by affecting the apoptosis pathway.
Genome-wide binding profile of HOTAIRM1 in K-R cells We further studied the regulation mechanism of HOTAIRM1. First, we separated the nucleus and cytoplasm and detected the expression of HOTAIRM1. We found HOTAIRM1 was mainly 
Fig. 3 HOTAIRM1 made cells develop dexamethasone resistance by influencing apoptosis. A Cell viability rate of control or HOTAIRM1 knockdown K-R cells after dexamethasone $(10 \mu \mathrm{M})$ treatment from day 0 to day 3. B Quantitation of Annexin V+/PI+ in K-R, K-R-scramble or K-R with HOTAIRM1 knockdown cells. All cells were treated with vehicle and $10 \mu \mathrm{M}$ dexamethasone for $48 \mathrm{~h}$ prior to staining. $\mathrm{C}$ Relative expression of BCL2 in control or HOTAIRM1 knockdown K-R cells. D Relative expression of BCL2L11 in control or HOTAIRM1 knockdown K-R cells. E Cell viability rate in control or HOTAIRM1 overexpression $\mathrm{K}-\mathrm{S}$ cells after dexamethasone $(10 \mu \mathrm{M})$ treatment from day 0 to day 3 . F Cell survival rate in control or HOTAIRM1 overexpression SKNO-1 cells after dexamethasone $(10 \mu \mathrm{M})$ treatment from day 0 to day 4 . G Significantly enriched pathways in genes affected by HOTAIRM1 knockdown in K-R cells (log2 Fold Change $>1$ or $<-1$ and $P$-value $<0.05$ ). The abscissa axis indicates the $-\log 10 P$-value, and the ordinate axis indicates Gene Ontology terms. Data information: Data were represented as mean \pm SD, $n=3$ (A-F). Difference between groups was assessed using Student's $t$-test: ${ }^{*} p<0.05,{ }^{* *} p<0.01,{ }^{* * *} p<0.001$, ns means no statistical significance.

distributed in the nucleus (Fig. 4A), which ruled out its role as a ceRNA (competing endogenous RNAs). Furthermore, we tested the HOXA family genes close to its genome location, and found that the expression of adjacent HOXA genes were not affected by HOTAIRM1 knockdown (Supplementary Fig. S4A). Therefore, we speculated that HOTAIRM1 may function as a trans-regulator.

Next, we adopted ChIRP-seq (chromatin isolation by RNA purification combined with high throughput sequencing) to determine the genome-wide binding sites of HOTAIRM1 [41, 42]. We designed ODD and EVEN probes specifically for HOTAIRM1 isoform 1, because isoform 1 decreased the most when HOTAIRM1 was knocked down (Supplementary Fig. S3A), which may contribute the most to the phenotype. Compared with the LacZ control, HOTAIRM 1 probes could strongly enriched HOTAIRM1 in ChIRP assay (Fig. 4B). Among the five isoforms, HOTAIRM1 -1 was significantly more abundant than other transcripts (Supplementary S4B). The genomic DNA fragments interacted with endogenous HOTAIRM1 were sequenced. Using MACS14 paired-end peak caller [43], we identified HOTAIRM1 binding sites and filtered the peaks by average coverage, correlation between odd and even probes, and fold of enrichment to get more reliable binding peaks. Finally, 489 peaks across whole genome were obtained (Fig. 4C, D) and 747 genes were annotated by GREAT (Genomic Regions Enrichment of Annotations Tool) [44] as the target genes for HOTAIRM1 binding (Supplementary Table S4). The focal peak range of HOTAIRM1 binding sites was $200-1000$ bp (Fig. 4E), that was similar to the ranges of IncRNAs HOTAIR and TERC binding peaks [41]. These HOTAIRM1 binding sites were widely distributed in the genome, and preferentially occurred in the intron and intergenic regions (Fig. 4F).

We compared the binding sites of HOTAIRM1 with known functional regulatory regions to gain more insight, including various histone modifications (H3K4me3, H3K4me1, H3K27me3, and H3K27ac) and DNA binding proteins (p300, CTCF) in different cells in the ENCODE (Encyclopedia of DNA Elements) database (GEO: GSE29611). We found that the binding sites of HOTAIRM1 had more overlap with the suppression marker H3K27me3 regions, and less intersection with the enhancer marker H3K4me1 and p300 regions (Fig. 4G), indicating that HOTAIRM1 may bind more in gene suppression region and less in activation region. In addition, HOTAIRM1 binding sites only had a little overlap with the H3K4me3 regions, which was consistent with our finding that HOTAIRM1 peaks rarely distributed in promoter region, implying that HOTAIRM1 may not play a regulatory role in promoter region in K-R cells.

In order to confirm the binding regions of HOTAIRM1 were transcriptional regulatory elements, we selected four binding site sequences located in four genes, two downregulated genes (FMNL2 and MACROD1) and two upregulated genes (PRDM5 and ARHGAP18) after HOTAIRM1 knockdown (Supplementary Fig. S4C), subcloned each to the upstream of a heterologous SV40 promoter in a pGL3 luciferase vector (Supplementary Fig. S4D). The luciferase activity of these constructs was then compared with that of the SV40 promoter alone after transient transfection into $\mathrm{K}-\mathrm{R}$ cells. Two sequences from HOTAIRM1 binding sites in the FMNL2 and MACROD1 increased the luciferase activities, while the other two binding sequences from PRDM5 and ARHGAP18 repressed the luciferase activities
(Fig. 4H). These results indicated that HOTAIRM1 binding sites played a role in transcriptional regulation, which could operate as either transcriptional enhancers or repressors.

\section{HOTAIRM1 affected RHOA/ROCK1 pathway by regulating ARHGAP18}

In order to further find the target genes of HOTAIRM1 that affect GC resistance, we screened out 38 genes which became similar to K-S after HOTAIRM1 knockdown in K-R. (Fig. 5A). We overlapped these 38 genes with 747 ChIRP target genes (Supplementary Table S4) to obtain four intersection genes (ARHGAP18, FMNL2, KCTD12, and PTPRF) (Fig. 5B). ARHGAP18 was highly enriched in K-S and was significantly upregulated in K-R after HOTAIRM1 knockdown, while ARHGAP18 knockdown did not affect the expression of HOTAIRM1 (Fig. 5C). Moreover, ARHGAP18 was inhibited by HOTAIRM1 binding, and its binding site was regarded as a repressor (Fig. 5D, E). Next, we investigated the dependence of the transcriptional activity of ARHGAP18 repressor element on HOTAIRM1. To achieve this, the luciferase reporters were co-transfected into K-R cells along with either a nontargeting control or a HOTAIRM1-targeting shRNA vector. Remarkably, knockdown of HOTAIRM1 suppressed the function of HOTAIRM1 binding sequence of ARHAGP18 as a transcriptional repressor (Fig. 5F). Therefore, ARHGAP18 was the target gene of HOTAIRM1 and could be inhibited by HOTAIRM1.

ARHGAP18 is a Rho GTPase-activating protein, belongs to RhoGAP family and contains classical RhoGAP domain on its C-terminus [45]. To further determine the role of ARHGAP18, we knocked down ARHGAP18 in K-S and found the cells showed stronger GC resistance than control (Fig. 6A-C). On the contrary, when ARHGAP18 was overexpressed in $\mathrm{K}-\mathrm{R}$, the cell survival rate decreased significantly after dexamethasone treatment (Fig. 6D), accompanied with a significant increase of BCL2L11 (Fig. 6E). After HOTAIRM1 knockdown in $\mathrm{K}-\mathrm{R}$, the expression of ARHGAP18 upregulated and the apoptosis-related gene (BCL2, BCL2L11) changed correspondingly (Fig. 6F). To investigate the role of HOTAIRM1- ARHGAP18 axis in glucocorticoid resistance, we knocked down ARHGAP18 in K-R-KD cells, and found that ARHGAP18 knockdown could rescued the decreased GC resistance in K-R-KD cells (Fig. 6G). The above results showed that ARHGAP18 could promote apoptosis. High expression of HOTAIRM1 inhibited ARHGAP18 and reduced the expression of BCL2L11, which conferred antiapoptotic ability on K-R cells.

As a member of RhoGAP family genes, knockdown of ARHGAP18 in K-S significantly activate RhoA (shown as RhoAGTP) (Fig. 6H). In K-R-KD cells, the ratio of active RHOA-GTP to total RHOA decreased (Fig. $6 \mathrm{H}$ ), and the phosphorylation level of myosin phosphatase (pMYPT1), which reflects the activity of the downstream target protein ROCK1, also decreased (Fig. 6l), indicating that RHOA/ROCK1 pathway was inhibited by HOTAIRM1 knockdown. ROCK1 inhibitor RKI-1447 could remarkably restore the sensitivity of K-R to GC (Fig. $6 \mathrm{~J}$ ). These results indicated that IncRNA HOTAIRM1 could activate RHOA/ROCK1 pathway through suppressing ARHGAP18, thereby enhancing the resistance of leukemic cells to GC-induced apoptosis.

\section{AML1 bound to the regulatory regions of HOTAIRM1 and ARHGAP18}

Next, we studied the upstream regulation of HOTAIRM1. Because of the myeloid-specific expression of HOTAIRM1 in the previous 
A

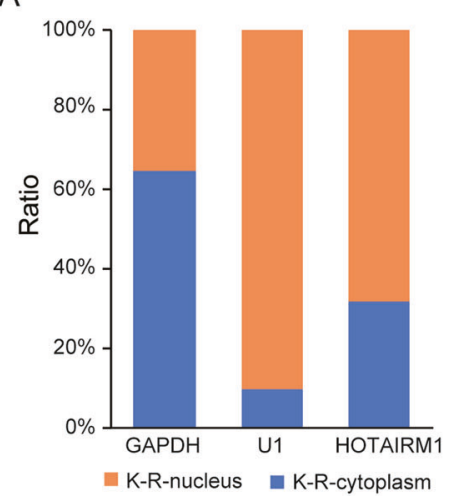

B
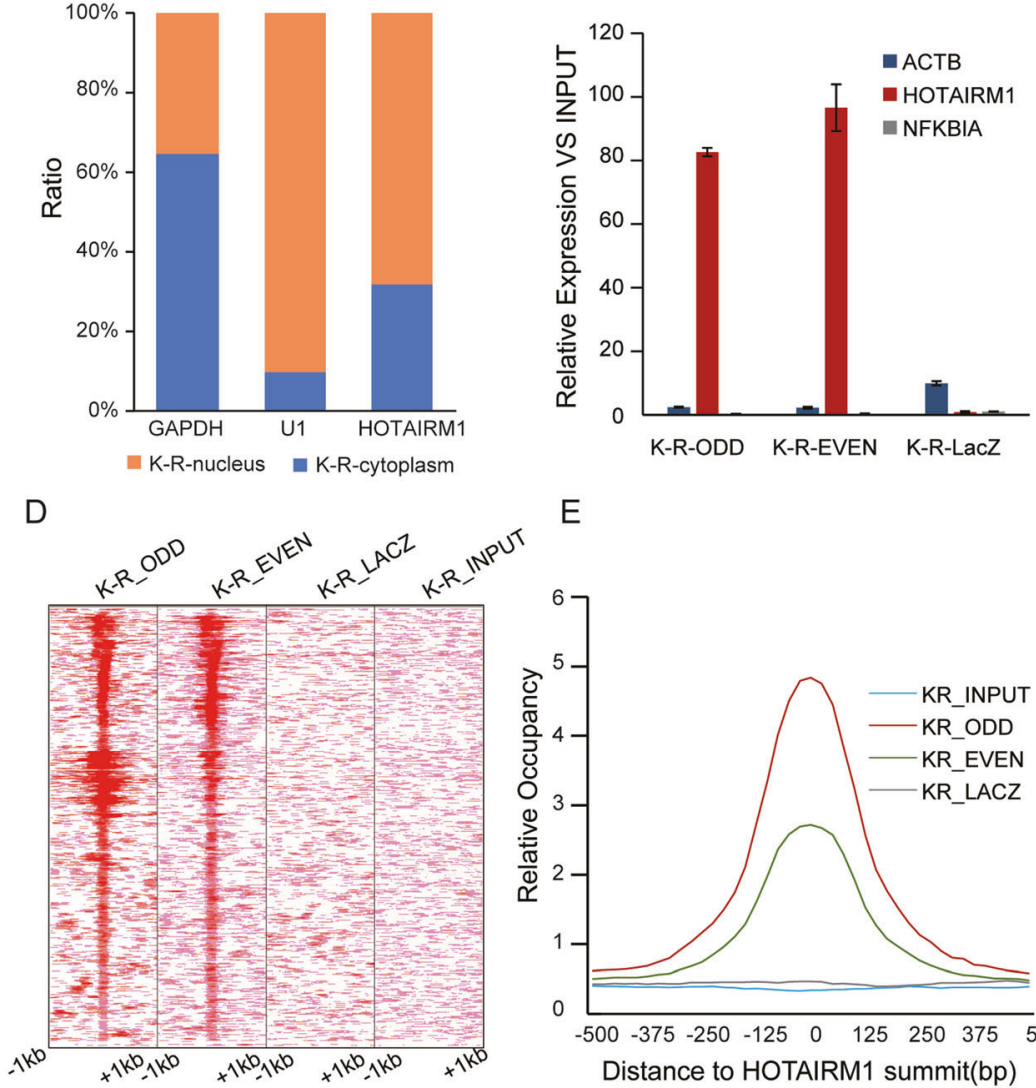

E

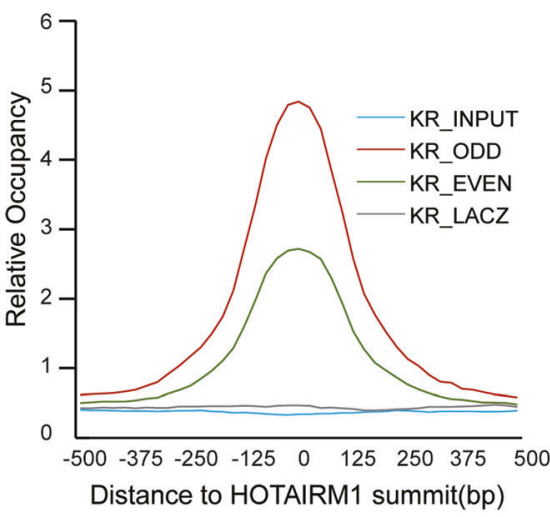

C $27363 \quad 151540 \quad 44433$

$\mathrm{F}$

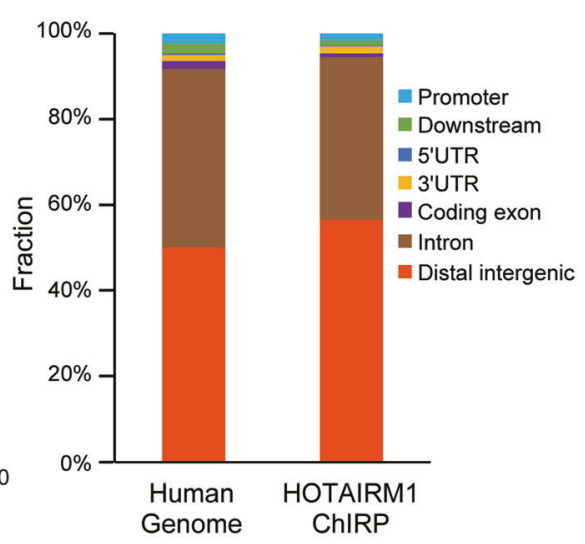

G

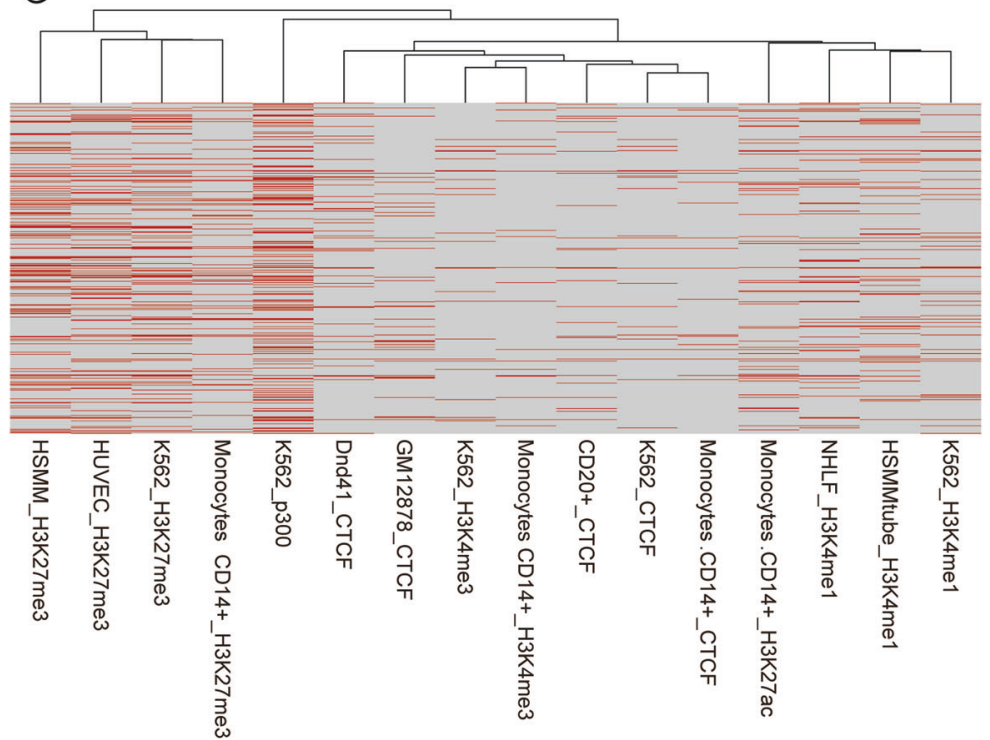

$\mathrm{H}$

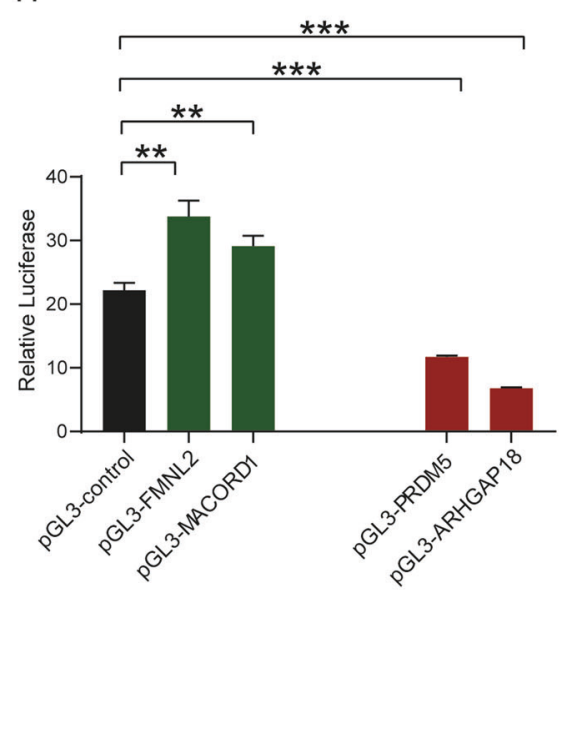

study [46], we utilized the ChIP-seq data of myeloid-derived CD14 + monocytes, H3K4me3 (GEO: GSM1003536) and H3K27ac (GEO: GSM1003559) generated by the ENCODE Project Consortium for analysis [47]. A 1508-bp region enriched H3K4me3 and H3K27ac was found around HOTAIRM1 transcription start site (TSS) (chr7:27095336-27096843) (Fig. 7A), which was considered as a promoter to predict transcription factors. According to JASPR database [48], we found seven putative binding sites for AML1 (Acute myeloid leukemia 1). It has been reported that abnormal expression of AML1 could enhance lymphocytes' response to glucocorticoid-induced apoptosis, but the underlying reason remains unclear [49].

Furthermore, we performed chromatin-immunoprecipitation and revealed that AML1 bound to about $500 \mathrm{bp}$ upstream to $1200 \mathrm{bp}$ downstream of the TSS of HOTAIRM1 (Fig. 7A), which coincided with H3K4me3 and H3K27ac binding sites on HOTAIRM1. We also found the expression of HOTAIRM1 was reduced after AML1 knockdown in K-R (Fig. 7B). To further investigate whether AML1 transactivates the 
Fig. 4 HOTAIRM1 functioned as a trans-regulator by binding to genomic DNA. A Subcellular fractionation of HOTAIRM1. GAPDH and U1 served as the controls of cytoplasm and nucleus, respectively. B HOTIRM1 RNA was enriched specifically by oligo nucleotide probes complementary to HOTAIRM1, compared to the LacZ control. High abundance gene ACTB and medium abundance gene NFKBIA were used as reference in qPCR. C HOTAIRM1 binding peaks were called by comparing with the binding sequences of LacZ control or input, respectively. Then 489 peaks were selected by the filtration criteria (Average coverage $>2$, Correlation $>0$, Fold Enrichment $>60$ ). D Heatmap of HOTAIRM1 ChIRPseq signal in peak regions. Each row represented a $2 \mathrm{~kb}$ genomic window centered on a HOTAIRM1 ChIRP peak; the peaks were aligned for HOTAIRM1 binding sites. Red color intensity indicated the number of ChIRP-seq reads. The equivalent genomic windows in control showed that ChIRP with LacZ probes retrieved no signal. E Metagene analysis of genomic regions aligned by 489 HOTAIRM1 ChIRP peaks showed focal HOTAIRM1 peaks. F HOTAIRM1 binding sites were enriched in distal intergenic region. G Hierarchical clustering of the HOTAIRM1 binding peaks (red) distribution on various cis-regulatory elements including repressed autosomal regions marked by $\mathrm{H} 3 \mathrm{~K} 27$ me3, active enhancer-like regions marked by H3K27ac and p300, CTCF binding regions, and promoter-like regions marked by H3K4me3. HSMM means human skeletal muscle myoblasts, HUVEC means human umbilical vein endothelial cells, Dnd41 means acute lymphocyte B cell leukemia cells, NHLF means human normal lung fibroblasts, K562 means myeloid leukemia cells, GM12878 means human B lymphocytes. H HOTAIRM1 binding sites acted as transcriptional regulatory elements. K-R cells were transfected with the indicated reporter constructs (Fig. S4C) in luciferase reporter assay. Luciferase activity was compared with that of the empty construct with $\mathrm{pGL} 3$ promoter. Data were represented as mean $\pm \mathrm{SD}, n=3$. Difference between groups was assessed using Student's $t$-test: ${ }^{*} p<0.05,{ }^{* *} p<0.01,{ }^{* * *} p<0.001$, ns means no statistical significance.

regulatory region of HOTAIRM1 through the above AML1 binding site, we cloned the binding site sequence into pGL3-basic luciferase reporter vector, and observed that the fragment could significantly enhance luciferase activity (Fig. 7C), confirming that this region was a transcriptional activation element. Furthermore, we knocked down AML1 in K-R and found a significant decrease in luciferase activity (Fig. 7C). These results indicated that AML1 could transactivate the HOTAIRM1 by binding to its promoter.

Analysis of ChIP-seq data of AML1 in K-R and K-S also revealed that there were two peaks in the first intron of ARHGAP18, namely $A 1$ and A2 (Fig. 7D), which were inserted into luciferase reporter vector containing SV40 promoter respectively to detect its transcriptional activity. Compared with the empty vector, the luciferase activity of the vector with $A 1$ fragment increased about three times, while the activity of the vector with $A 2$ was almost unchanged. After AML1 knockdown, the luciferase activity of the vector with A1 fragment decreased to nearly empty vector level, while the luciferase activity of the vector with $A 2$ remained unchanged (Fig. 7E). These results showed that the $A 1$ region in ARHGAP18, rather than the $A 2$, was a transcriptional activation element and could be activated by AML1 binding.

\section{Interaction of HOTAIRM1 and AML1}

LncRNAs usually form complexes with proteins. We performed RNA immunoprecipitation assay (RIP) to explore whether AML1 directly interacted with HOTAIRM1. RBM34 protein was used as a positive control, since it contains two subdomains of RNA recognition motifs that can bind to RNA. We incubated the K-R cell lysate with magnetic beads coated with RBM34, AML1, and IgG protein antibodies, eluted the protein-bound RNA and detected HOTAIRM1 by qPCR. We found HOTAIRM1 was highly enriched in AML1 binding RNAs, indicating AML1 could strongly bind to IncRNA HOTAIRM1(Fig. 7F, G).

Next, we wanted to explore whether the interaction of HOTAIRM1 and AML1 could affect the transcription factor activity of AML1. We performed ChIP-qPCR on the A1 fragment of ARHGAP18 with AML1 antibody in K-R cells, and found that after HOTAIRM1 knockdown in K-R, the binding of AML1 to A1 increased (Fig. $7 \mathrm{H})$. Since $A 1$ was a transcriptional activation element and could be activated by AML1 binding, the increased binding of AML1 to A1 caused by HOTAIRM1 knockdown enhanced the transcription of ARHGAP18. The above results suggested that the interaction of HOTAIRM1 and AML1 attenuates the binding of $A M L 1$ to the $A 1$ region of $A R H G A P 18$ gene, thereby reducing the transcriptional activation of $\mathrm{ARH}$ GAP18 by AML1.

Based on all our findings, we summarized the mechanism of HOTAIRM1 on GC resistance in Fig. 8 (Fig. 8).

\section{DISCUSSION}

The previous studies on the mechanism of $\mathrm{GC}$ resistance focused mostly on GC-GR. However, GR mutations or aberrant expression were absent in many $G C$ resistance cases, suggesting there are other unknown reasons. In our study, we constructed a cell model to simulate the occurrence of $\mathrm{GC}$ resistance in vitro. Based on this model, we found that IncRNA HOTAIRM1 was upregulated in GCresistant K-R cells and activated RHOA/ROCK1 signaling pathway to resist GC-induced apoptosis, while two IncRNAs GAS5 and SRA, which were reported to be related to $G C$ resistance by activating the upstream GR, had no significant difference between K-R and K-S. Our study reported for the first time that a IncRNA can directly activate the downstream antiapoptotic pathways, and make cells develop GC resistance. This finding reflected the specificity of IncRNA function in different systems and the complexity and heterogeneity of the causes of GC resistance, which helps us to understand the molecular mechanism of GC resistance more comprehensively. In addition, HOTAIRM1 may also be used as a marker to monitor the occurrence of $G C$ resistance and a potential target to reverse $\mathrm{GC}$ resistance.

RHOA/ROCK1 signaling pathway plays a vital role in cell survival and is closely related to the pathogenesis of various diseases. When glucocorticoids are used, targeted inhibition of this pathway may help optimize glucocorticoid therapy. In addition, the influence of this pathway on cell apoptosis under other conditions or drugs needs further study.

HOTAIRM1 was discovered as a myeloid-specific long noncoding RNA in promyelocytic leukemia cell [46], which was upregulated during differentiation induced by all-trans-retinoic acid [39]. In this study, we revealed the antiapoptotic effect of HOTAIRM1 in GC resistance and explored its mechanism. So far HOTAIRM1 has been reported to play various roles in many types of cancers, including non-small cell lung cancer, glioma, colorectal cancer, endometrial cancer, ovarian cancer, etc., but most of the mechanisms are not clear [50,51, 38, 52]. LncRNAs can interact with DNA, RNA or protein, and regulate gene expression in close proximity (cis-acting regulation) or target distant transcriptional activators or repressors (trans-acting) [53-56]. We obtained genome-wide binding sites of HOTAIRM1 by RNA immunoprecipitation for the first time, and further confirmed HOTAIRM1 could function in trans. However, HOTAIRM1 binding to chromatin to inhibit ARHGAP18 transcription may require other proteins, which need further investigation.

It has been reported that IncRNAs can bind and sequester transcription factors away from their target chromatin regions. For example, PANDA inhibited the expression of apoptotic genes by sequestering the transcription factor NF-YA from occupying target gene promoters [57]. In our study, HOTAIRM1 could interact with 
A

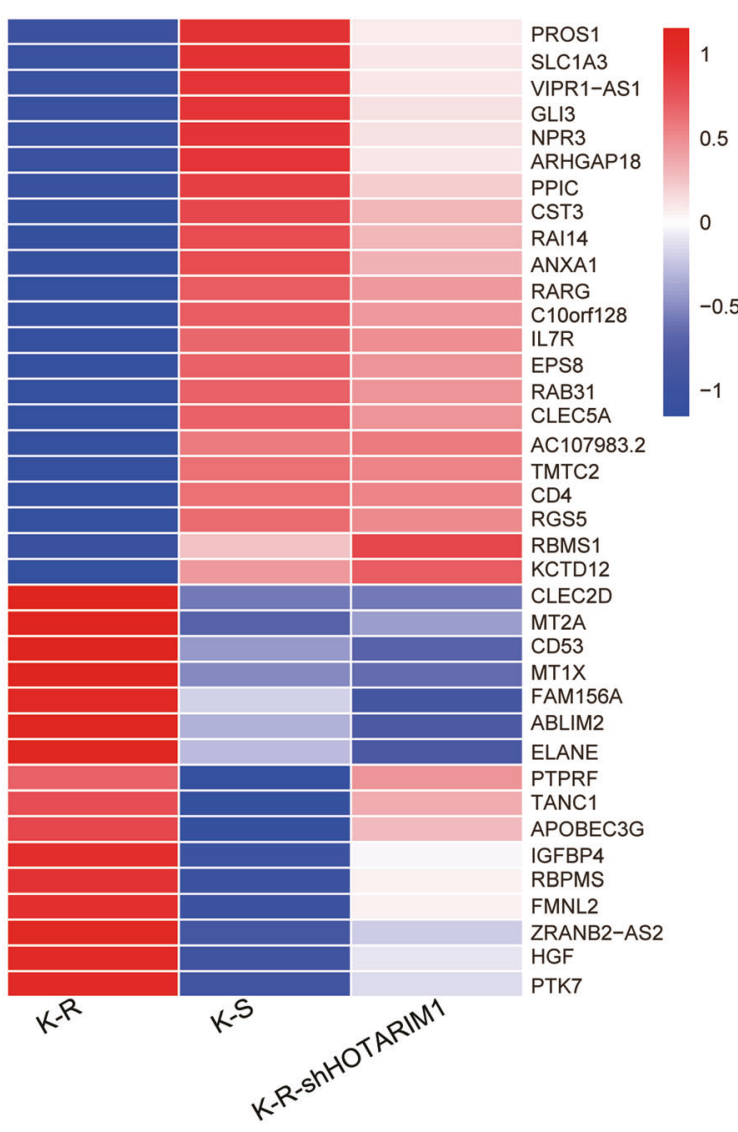

D

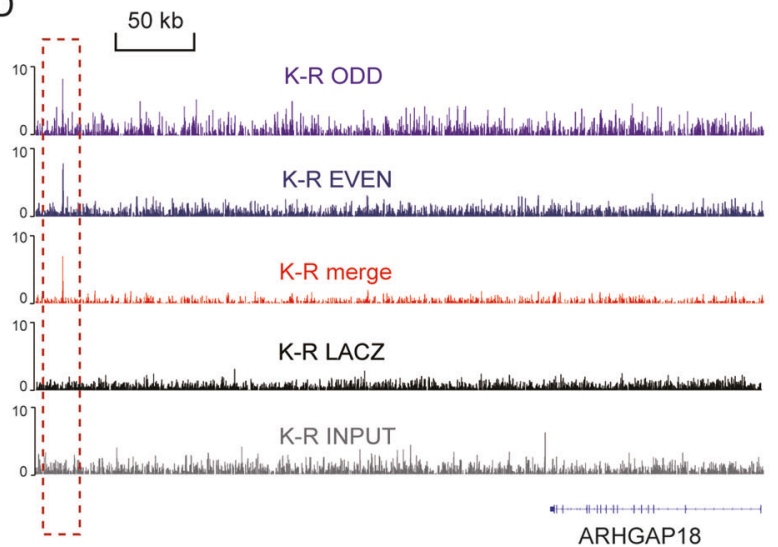

B

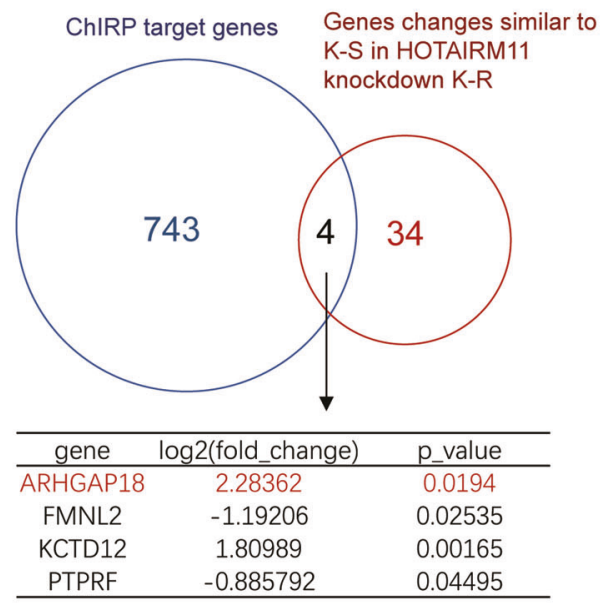

C

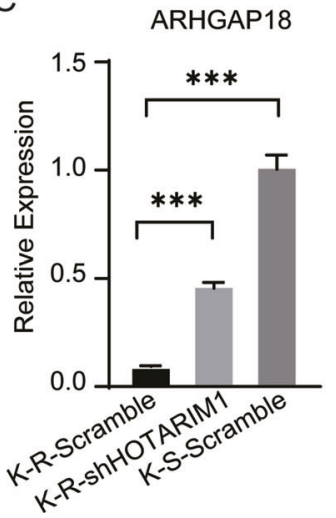

E

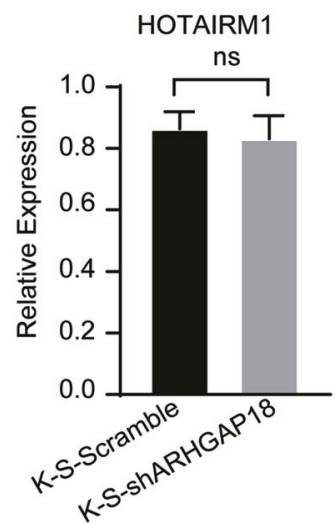

F

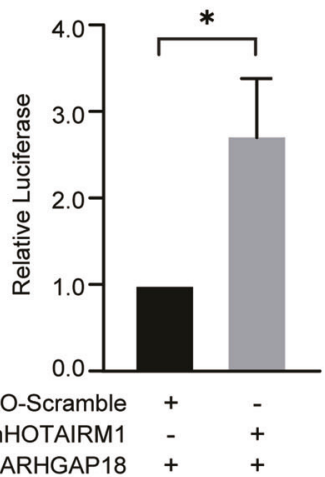

Fig. 5 ARHGAP18 was suppressed by HOTAIRM1 binding. A Heatmap of the genes expression level, which may be regulated by HOTAIRM1 and contribute to GC resistance. B ARHGAP18 were selected by overlapping the ChIRP target genes and the genes, which became similar to K$\mathrm{S}$ after HOTAIM1 knockdown in K-R. C The expression levels of ARHGAP18 were measured in K-S-scramble, K-R-scramble, and K-R with HOTAIRM1 knockdown using qRT-PCR (left). HOTAIRM1 was not affected by the knockdown of ARHGAP18 in K-S (right). D Tracks of the HOTAIRM1 binding peaks near the ARHGAP18 gene locus in ChIRP-seq data. The dark blue represents the even probe group, the purple represents the odd probe group, the red represents the peak of the merged odd and even probe data, the gray represents the LacZ probe group, and the black represents the input, the red dashed box represents the binding peak. E K-R cells were transfected with the HOTAIRM1 binding sequence of ARHGAP18 in luciferase reporter assay. Luciferase activity was compared with that of the empty construct with pGL3 promoter. F pGL3-ARHGAP18 were co-transfected into K-R cells with either nontargeting control vectors or HOTAIRM1-targeting shRNA vectors. Data information: Data were represented as mean $\pm S D, n=3(\mathbf{C}, \mathbf{E}-\mathbf{F})$. Difference between groups was assessed using Student's $t$-test: ${ }^{*} p<0.05,{ }^{* *} p<0.01,{ }^{* *} p<0.001$, ns means no statistical significance.

the AML1 protein and hinder the positive regulation of AML1 on ARHGAP18 transcription.

In addition, we found HOTAIRM1 was regulated by AML1, which is another upstream regulator after PU.1 was reported to regulate HOTAIRM1 [58]. AML1 can enhance the response of lymphocytes to glucocorticoids, but the reason is unclear [49]. Our study detailed the intermediate regulation of AML1 to GC resistance. Moreover, AML1 inhibited its own activation of ARHGAP18 by increasing the expression of HOTAIRM1, which fully demonstrates the complex and delicate regulation of IncRNA involved in eukaryotic systems. 
A

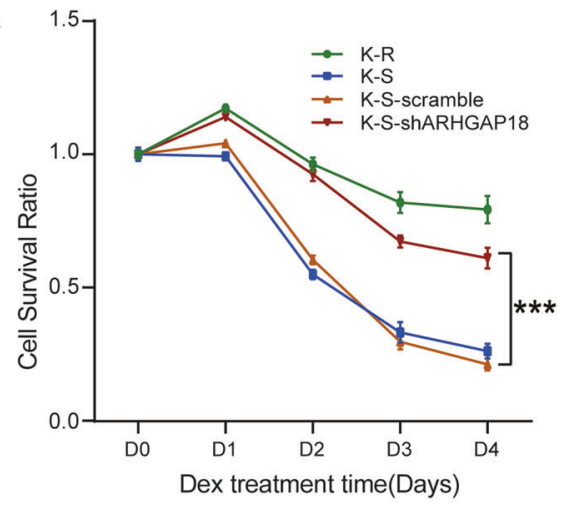

B

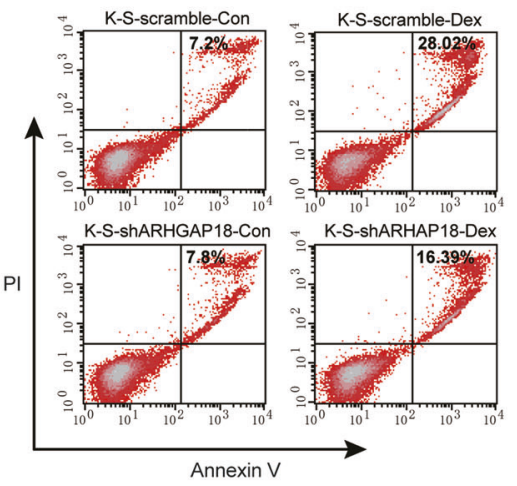

C

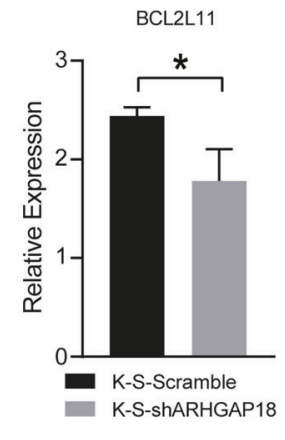

D

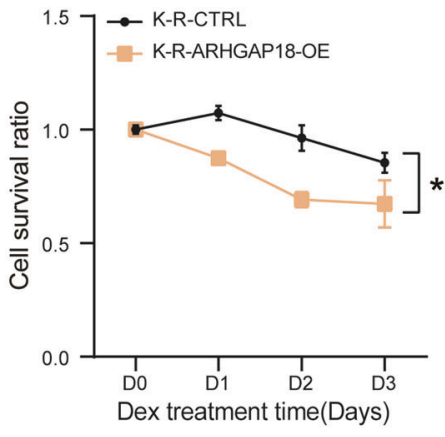

G

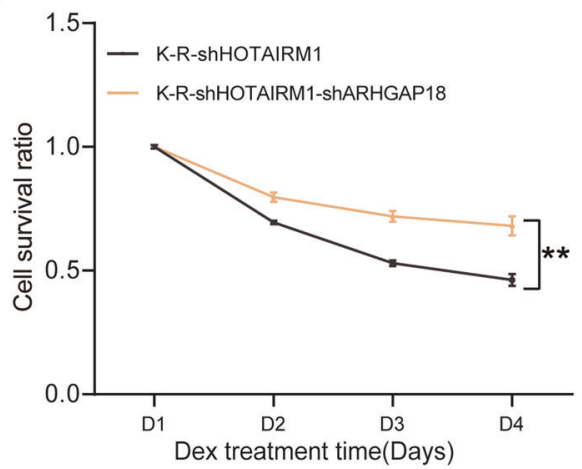

$E$

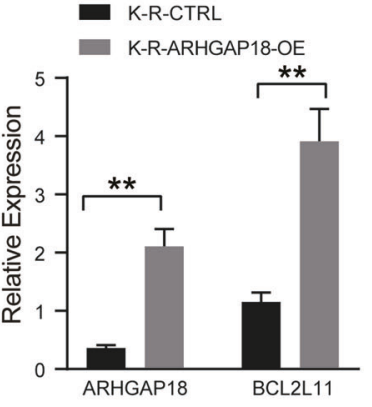

$\mathrm{F}$
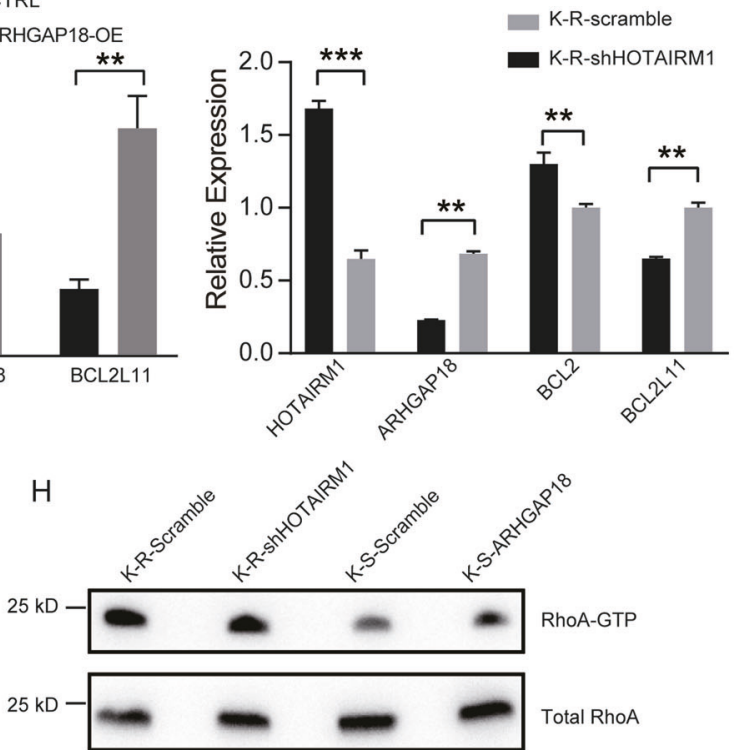

$\begin{array}{lllll}1 & 0.8 & 0.3 & 0.5 & \begin{array}{l}\text { Relative RhoA-GTP/ } \\ \text { Total RhoA }\end{array}\end{array}$

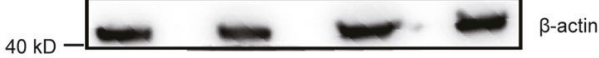

I

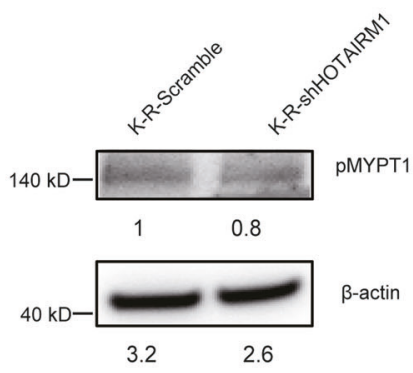

In conclusion, our study found that long noncoding RNA HOTAIRM1 can resist GC-induced apoptosis, and elucidated the mechanism from the perspective of upstream and downstream regulation of HOTAIRM1, revealing an epigenetic cause of glucocorticoid resistance in leukemia.

\section{MATERIALS AND METHODS}

Cell culture

Human leukemia cell lines: K562, U937, THP1, Jurkat, RS4;11, and HEK-293 T cells were purchased from American Type Culture Collection (ATCC, Manassas, VA, USA.). Kasumi-1 and SKNO-1 were gifted by Dr. Janet D. 
Fig. 6 ARHGAP18 increased GC sensitivity by RHOA/ROCK1 pathway. A Cell viability rate in control or ARHGAP18 knockdown K-S cells after Dex $(10 \mu \mathrm{M})$ treatment from day 0 to day 4. B Flow cytometry analysis of Annexin $\mathrm{V}$ and PI in control or ARHGAP18 knockdown K-S cells. Both cells were treated with vehicle and $10 \mu \mathrm{M}$ dexamethasone for $48 \mathrm{~h}$ prior to staining. C Relative expression of BCL2L11 in control or ARHGAP18 knockdown K-S cells. D Cell viability rate in control and ARHGAP18 overexpression K-R cells after Dex (10 $\mu$ M) treatment from day 0 to day 3 . E Relative expression of BCL2L11 in control or ARHGAP18 overexpression K-R cells. F Relative expression of ARHGAP18, BCL2, and BCL2L11 in control or HOTAIRM1 knockdown K-R cells. G Cell viability rate after Dex $(10 \mu \mathrm{M})$ treatment from day 0 to day 4 . HOTAIRM1 knockdown K-R cells decreased gradually to $50 \%$ from day 0 to day 4 . ARHGAP18 knockdown rescued the decrease of GC resistance caused by the knockdown of HOTAIRM1. H Western blot showing RhoA-GTP and total RhoA in different cells. The protein bands were analyzed in grayscale using Image J software to determine the ratio of RhoA-GTP to total RhoA. The $\beta$-actin was internal control. I Analysis of MYPT phosphorylated levels in control and HOTAIRM1 knockdown K-R cells. The protein bands were analyzed with Image J software to calculate the relative grayscale value of proteins between samples. The $\beta$-actin was the internal control. J Cell viability rate of K-R cells treated with ROCK1 inhibitors RKI-1447 $(1 \mu \mathrm{M})$, Dex $(10 \mu \mathrm{M})$ and combined drugs for 1-5 days, respectively. Data information: Data were represented as mean \pm SD, $n=3(\mathbf{A}, \mathbf{C}, \mathbf{D}-\mathbf{F}, \mathbf{I})$. Difference between groups was assessed using Student's $t$-test: ${ }^{*} p<0.05,{ }^{* *} p<0.01,{ }^{* *} p<0.001$, ns means no statistical significance.

A

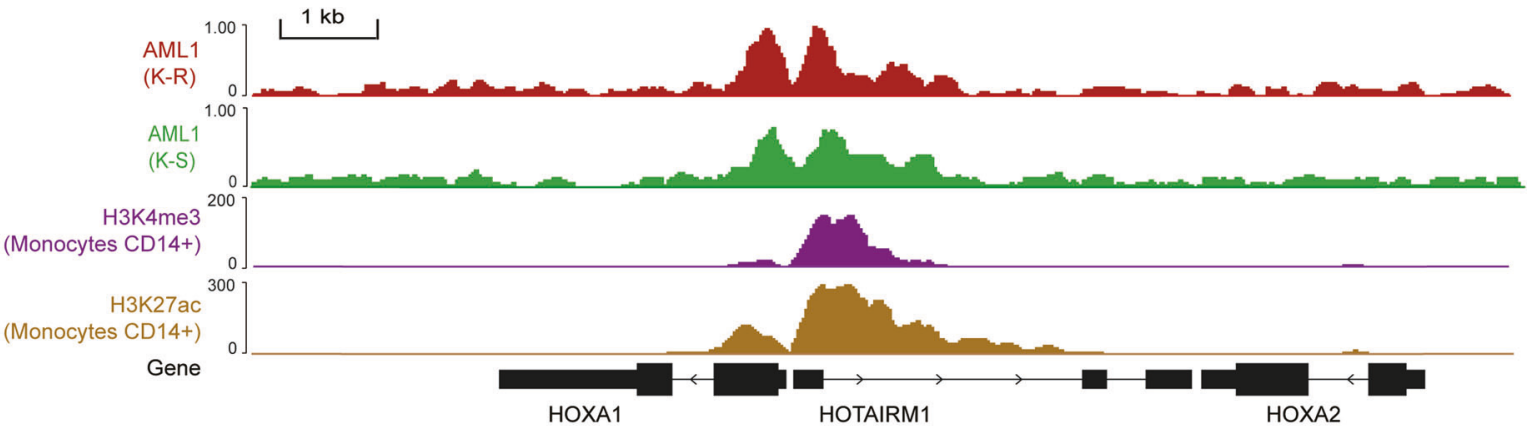

$\mathrm{B}$

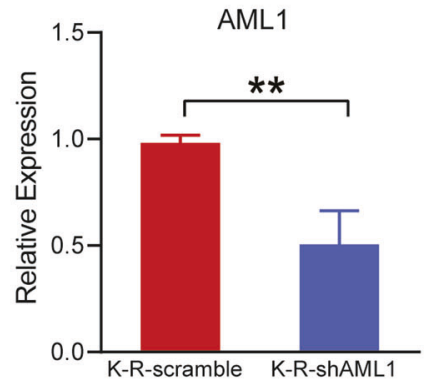

$\mathrm{D}$

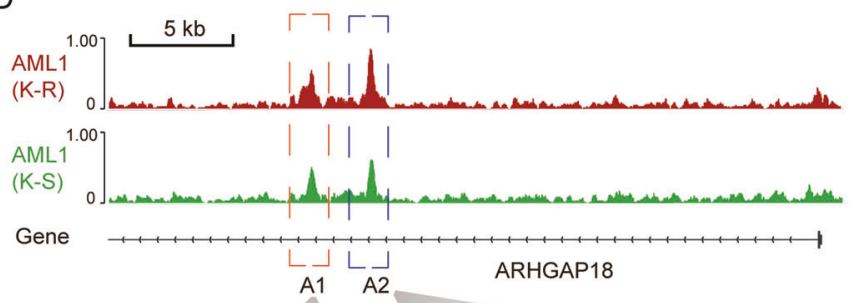

E

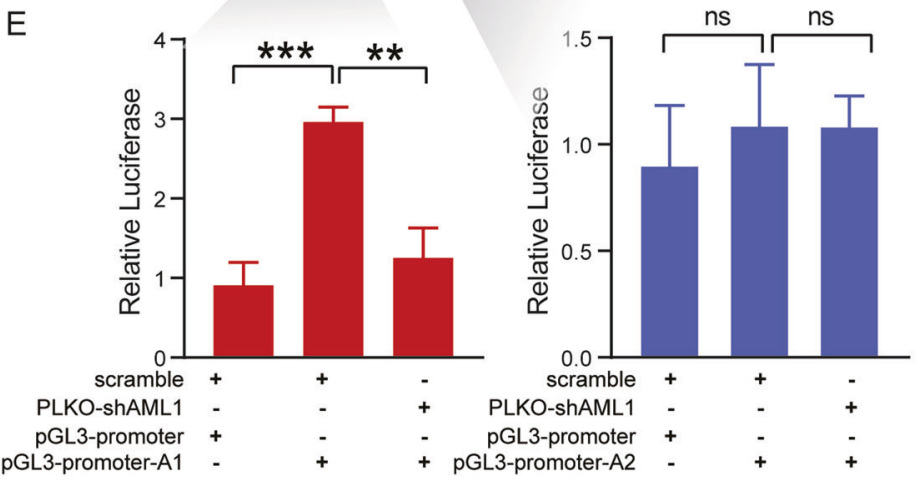

F

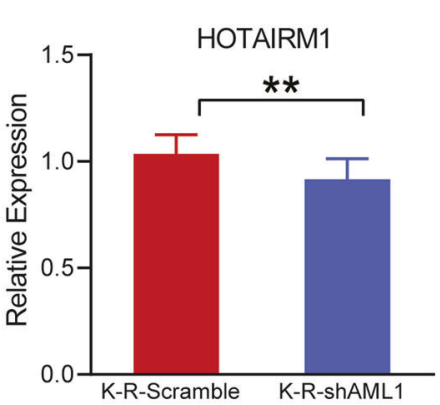

PLKO-shAML1 pGL3-HOTAIRM1-promoter
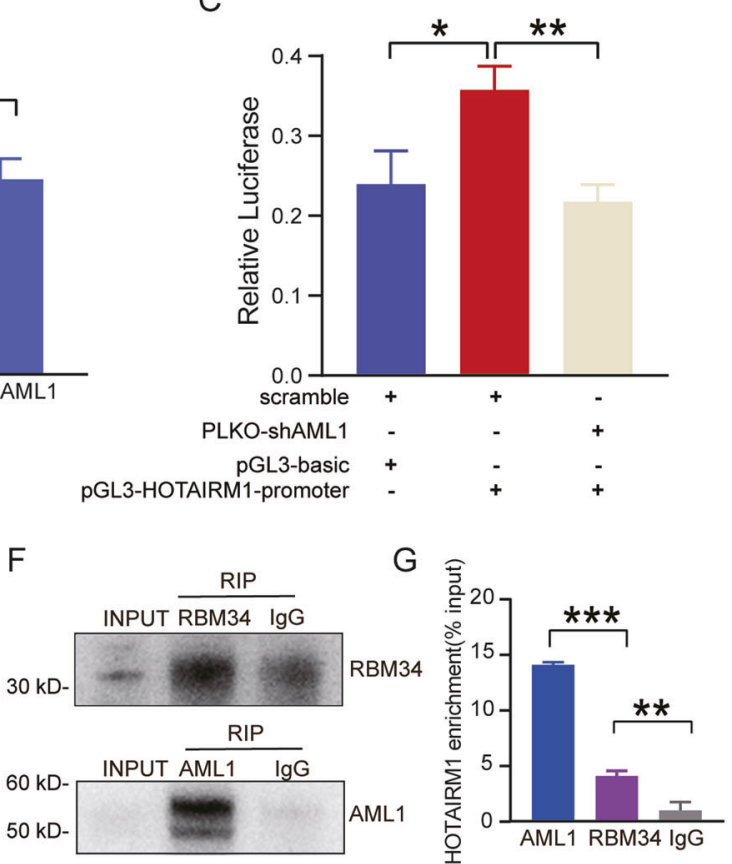

$\mathrm{H}$

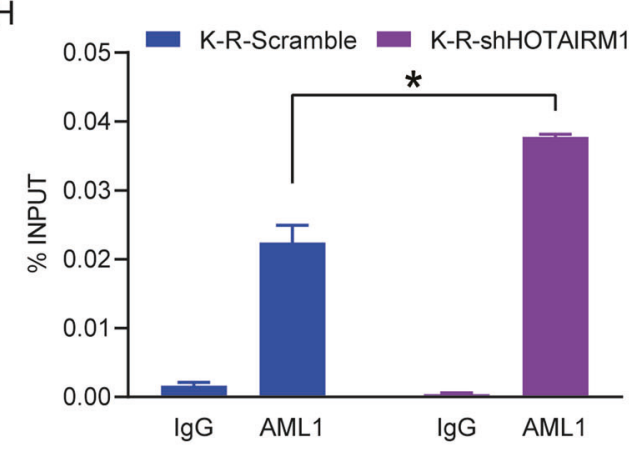


Fig. 7 Interaction between AML1 and HOTAIRM1. A Tracks of binding peaks in HOTAIRM1 gene locus in various ChIP-seq data. The binding signals of AML1 in K-R and K-S cells were shown in red and green, respectively. The binding signals of H3K27ac and H3K4me3 in CD14+ monocytes were shown in purple and orange, respectively. B Validation of AML1 knockdown efficiency in AML1 knockdown K-R cells by qRTPCR (left). Relative expression levels of HOTAIRM1 in control and AML1 knockdown K-R cells by qRT-PCR (right). C Luciferase activities were detected in control and AML1 knockdown K-R cells to confirm the binding of AML to HOTAIRM1 promoter region and the transcription regulatory activity of AML1. D Tracks of two AML1 binding peaks in the ARHGAP18 intron region, labeled A1 and A2. E Luciferase activities were detected in control and AML1 knockdown K-R cells to compare the transcriptional activity of A1 and A2 fragments and determine whether they were AML1 dependent. A1 caused enhanced luciferase activity compared with empty vector with pGL3 promoter, and the activity decreased after AML1 knockdown. A2 did not significantly change luciferase activity compared with empty vector and remained almost unchanged after AML1 knockdown. F Using RBM34 and AML1 antibodies to pull-down protein complexes in RIP assay. Western blot was performed with corresponding antibodies to determine the efficiency of pull-down. G RNAs extracted from the complexes pulled down by RBM34, AML1, and IgG antibodies were subjected to qPCR to detect the enrichment of HOTAIRM1 relative to the input (RBM34 as the positive control, IgG as the negative control). $\mathbf{H}$ ChIP was performed with AML1 antibody in control and HOTAIRM1 knockdown K-R cells. The A1 fragment bound by AML1 on ARHGAP18 was detected by qPCR to calculate the enrichment ratio relative to the input. Data information: Data were represented as mean $\pm \mathrm{SD}, n=3(\mathbf{B}-\mathbf{C}, \mathbf{E}, \mathbf{G}-\mathbf{H})$. Difference between groups was assessed using Student's $t$-test: ${ }^{*} p<0.05,{ }^{* *} p<0.01$, ${ }^{* * *} p<0.001$, ns means no statistical significance.

Rowley from University of Chicago. CEM-C1-15, CEM-C7-14 were gifted by Dr. Rheem D. Medh from California State University. Cell lines have been authenticated. Kasumi- 1 cells were cultured in complete RPMI 1640 medium containing $20 \%$ fetal bovine serum (FBS) (Gibco, Massachusetts, USA) and $1 \%$ penicillin/streptomycin at $37^{\circ} \mathrm{C}$. SKNO-1, K562, U937, THP1, CEM-C1-15, CEM-C7-14, Jurkat, RS4;11 cells were cultured in complete RPMI 1640 medium with $10 \% \mathrm{FBS}$, and $1 \%$ penicillin/ streptomycin at $37^{\circ} \mathrm{C}$. HEK-293 T cells were cultured in DMEM containing 10\% FBS. All cells were cultured in a humidified atmosphere containing $5 \% \mathrm{CO}_{2}$ at $37^{\circ} \mathrm{C}$, and was tested no mycoplasma contamination.

\section{Generation of Glucocorticoid-resistant cell lines}

Equal amounts of Kasumi- 1 cells $\left(5 \times 10^{6}\right.$ cells) in exponential growth $\left(\sim 1.5 \times 10^{6}\right.$ cells $\left./ \mathrm{ml}\right)$ were collected and centrifuged at $1000 \mathrm{rpm}(\sim 120 \times \mathrm{g})$ for $5 \mathrm{~min}$. Cell pellets were resuspended in $15 \mathrm{ml}$ complete medium with either $1 \mu \mathrm{M}$ Dex, or $0.1 \% \mathrm{EtOH}(\mathrm{v} / \mathrm{v})$ as vehicle control. Cells were then seeded into two T75 flasks with an initial cell density of $\sim 3 \times 10^{5}$ cells $/ \mathrm{ml}$. Most of the Dex treated Kasumi-1 cells were died post the first wave of treatment (3 days). Scarcely any change, however, could be seen in those $\mathrm{EtOH}$ treated cells. Therefore, Dex treated cells were all collected by centrifugation as mentioned above, and were resuspended in $15 \mathrm{ml}$ fresh medium with $1 \mu \mathrm{M}$ Dex. During the first four rounds (total 12 days), all Dex treated cells were collected, while the EtOH treated cells were normally maintained. From the fifth to seventh round, cells became less sensitive to the inhibition effect of Dex, hence subcultured every 3 days with a subcultivation ratio of 1:3. After screening of the Kasumi- 1 cells for 21 days (seven rounds) altogether, both Dex and EtOH treated cells were transferred into complete medium and normally maintained for another 25 days. GC sensitivity of the Dex treated cells was analyzed by MTS-based cytotoxicity assay on the 13th, 16th, and 25th day upon withdrawal of Dex. $\mathrm{EtOH}$ and Dex treated cells were then defined as K-S (Kasumi-1 Sensitive) and K-R (Kasumi-1 Resistant) cells, respectively.

\section{Plasmids, reagents, quantitative PCR, and western blotting} HOTAIRM 1 sequence was amplified by PCR (polymerase chain reaction), and then subsequently cloned into PCDH-CMV-MCS-EF1-PURO (System Biosciences, Palo Alto, CA) at EcoR I and BamH I sites. The HOTAIRM1 shRNA hairpins were cloned into $\mathrm{pLKO}$ lentivirus system. All shRNA oligo sequences were listed in Supplementary Table S5. High fidelity enzyme Phusion was used for PCR amplification, primers of gene overexpression were listed in Supplementary Table S6. All PCR products were verified by DNA sequencing. Specific antibodies used in this work, including mouse GR (sc-393232) (Santa Cruz Biotechnology, Texas, USA), rabbit AML1(\#4334) (Cell Signaling Technology, Massachusetts, USA), mouse $\beta$-actin (M1210-2) (HangZhou HuaAn Biotechnology, China), rabbit Phospho-MYPT1 (Thr853) (\#4563) (Cell Signaling Technology, Massachusetts, USA), rabbit RhoA (ARH04) (Cytoskeleton, Denver, USA). Other reagents were used include RU486 (E8875) (Sigma-Aldrich, China) and RKI-1447 (H6278) (Sigma-Aldrich, China), puromycine (A11138-03) (Gibco, Massachusetts, USA). All qPCR primers were designed with Primer 5.0 and synthesized by Sangon Biotech (Beijing, China) (Supplementary Table S7, S8). qPCR was performed using SYBR Green PCR Master Mix (\#kk4601) (KAPA Biosystems, Woburn, USA) by Two-step method for three technical replicates, and the significance was determined by two-tailed $t$-test. Each experiment was repeated at least three times independently. Western blotting was carried out with standard protocol. The band intensities on western blot were quantified with Image $J$ and each control was normalized to obtain the ratio of protein level.

\section{Subcellular fractionation}

Fractionation of the cells to separate nucleus and cytoplasm was performed using NE-PER Nuclear and Cytoplasmic Extraction Reagents (\#78833) (Thermo Scientific, Massachusetts, USA) following the manufacturer's protocol. The separation efficiency of the two fractions was assessed by $\mathrm{qPCR}$ amplification with primers targeting the nucleus-specific $\mathrm{U} 1$ and cytoplasmic specific GAPDH.

\section{Chromatin-immunoprecipitation (ChIP)}

$\mathrm{K}-\mathrm{R}$ and $\mathrm{K}-\mathrm{S}$ cell were exposed to $10^{-6} \mathrm{M}$ of dexamethasone or corresponding vehicle ethanol for $8 \mathrm{~h}$. They were then fixed by formaldehyde with $1 \%$ final concentration and incubated for $10 \mathrm{~min}$ at room temperature with rotation. The crosslinking reactions were quenched with $0.125 \mathrm{M}$ glycine for $5 \mathrm{~min}$ at room temperature and washed twice with ice-cold PBS (phosphate buffer saline). And ChIP was performed by co-precipitating the DNA/protein complexes with a GR antibody (sc393232) (Santa Cruz Biotechnology, Texas, USA) and a rabbit control lgG (Santa Cruz Biotechnology, Texas, USA). DNA from protein-associated complexes and corresponding input samples was recovered and purified using QIAquick PCR Purification Kit (QIAGEN, Hilden, Germany). For ChIPseq, the ChIP DNA samples were dissolved in $20 \mu \mathrm{l}$ water and sequenced with a $20 \mathrm{M}$ reads per sample using Hiseq2500 platform.

\section{Construction and transduction of shRNA-expressing lentiviral vector}

The shRNA-targeting sites ( $21 \mathrm{nt})$ of HOTAIRM1 transcript were selected on the shRNA selection server of the Whitehead Institute for Biomedical Research, and their specificities were detected by BLAST. Lentiviral vectors expressing short hairpin RNAs (shRNAs) targeting the selected HOTAIRM1 sites (Supplementary Table S5) were constructed by inserting each shRNA cassette into a pLKO-TRC backbone plasmid (Addgene plasmid 10878). A control vector expressing a scramble shRNA sequence (adopted from Addgene plasmid 1864) was constructed on the same backbone plasmid. Resultant pLKO.1-TRC-shHOTAIRM1 and control pLKO-TRC scramble shRNA lentiviral vectors were prepared and pseudotyped in the HEK293T cell line by co-transfection with packaging plasmids pMD2.G (Addgene plasmid 12259) and psPAX2 (Addgene plasmid 12260) using FuGENE ${ }^{\circledR} 6$ Transfection Reagent (Promega, Madison, Wisconsin, USA). For transduction, $\mathrm{K}-\mathrm{R}$ cells were suspended in a medium containing lentiviral supernatant and cultured at $37^{\circ} \mathrm{C}$ for $48-72 \mathrm{~h}$. For generation of stably transduced cell clones, the transgenic cells were inoculated in puromycin-containing medium for 5-7 days, and showed HOTAIRM1 knockdown rate of over 70\% by qRT-PCR.

\section{RNA-seq}

Total RNAs were isolated using TRIzol reagent (Invitrogen, Shanghai, China). Construction of ribosomal removal transcriptome library and RNAseq was carried out using Illumina HiSeq2500 (Novo gene, Beijing, China). 


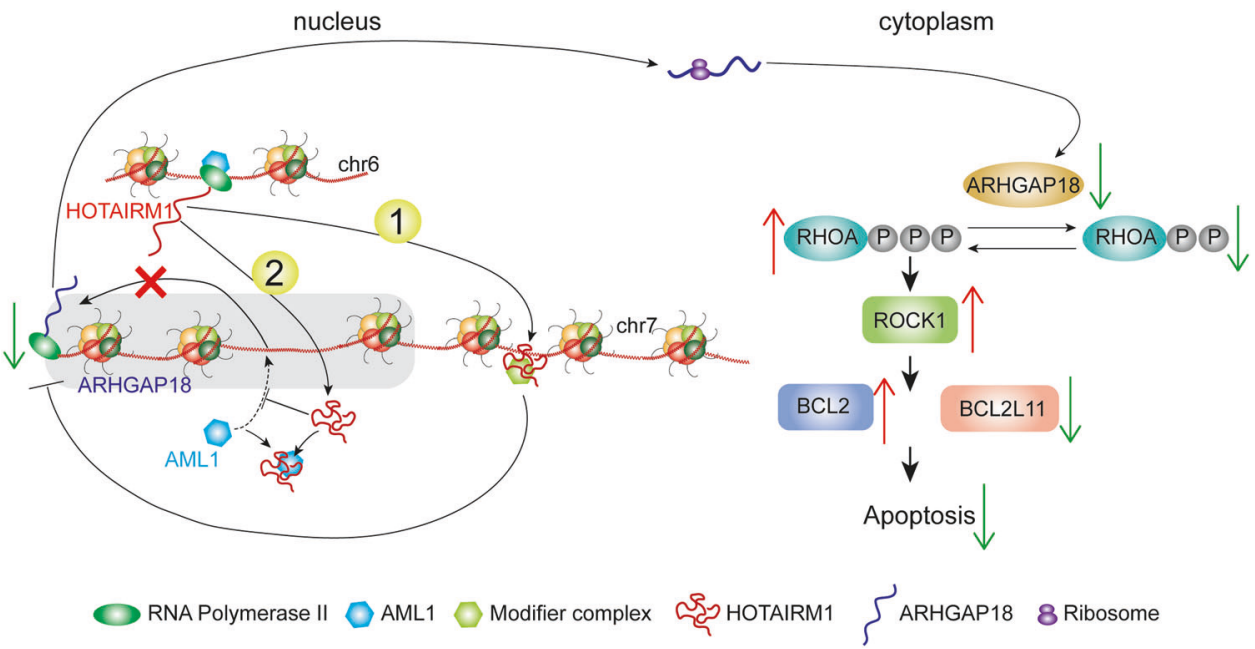

Fig. 8 Schematic diagram of HOTAIRM1 working mechanism. The transcription of HOTAIRM1 is regulated by the binding of AML1 to its promoter region. As a trans factor, HOTAIRM1 inhibits the transcription of ARHGAP18 in the nucleus in two ways: (1) It binds to the chromatin site downstream of ARHGAP18 gene to inhibit the transcription of ARHGAP18. HOTAIRM1 may interact with other proteins to form a complex. (2) It binds to the AML1 protein to keep AML1 away from its target chromatin region, thereby preventing the gene transcription activity of AML1. After the transcription of ARHGAP18 is suppressed, its protein expression level is decreased, which increases the active form of RhoAGTP and activates the RHOA/ROCK1 signaling pathway. Subsequently, the increase of the antiapoptotic gene BCL2 and the decrease of the proapoptotic gene BCL2L11 eventually lead to the decrease of apoptosis.

\section{Chromatin isolation by RNA purification (ChIRP-seq) and analysis}

The ChIRP procedure was performed as previously described [41]. DNA probes (Supplementary Table S9) with 20 bp biotinylated at the 3' end were used (Sangon Biotech, Beijing, China). About $1 \times 10^{8} \mathrm{~K}$-R cells were harvested and washed twice with frozen PBS. Then, cells were resuspended in $4 \mathrm{ml}$ PBS. For chemical crosslinking, cells were fixed on plate with appropriate amounts of $3 \%$ formaldehyde in PBS for $30 \mathrm{~min}$ at room temperature. Crosslinking was then quenched with $0.125 \mathrm{M}$ glycine for $5 \mathrm{~min}$. Cells were rinsed again with PBS, and pelleted at $800 \times g$ for $5 \mathrm{~min}$, followed by two times of frozen PBS wash. Crosslinked cell pellets were resuspended in lysis buffer $(50 \mathrm{mM}$ Tris-Cl, $\mathrm{pH} 7.5$, $10 \mathrm{mM}$ EDTA, 1\% SDS) with addition of protease inhibitor cocktail, PMSF and RNaseOut. Chromatin fractions were sonicated to have average DNA size ranging from $200-1000 \mathrm{bp}$. The supernatant was saved for probe hybridization. For each hybridization reaction, about $10 \mathrm{pmol}$ of biotinylated probes were used. About $1 / 4$ volume of $5 \times$ Hybridization buffer (50 mM Tris-Cl, pH 7.5, $10 \mathrm{mM}$ EDTA, 1\% SDS, $1.5 \mathrm{M} \mathrm{NaCl}, 50 \%$ formamide), was added and incubated at $37^{\circ} \mathrm{C}$ by end-to-end rotation overnight. Then, $50 \mu \mathrm{l}$ of prebalanced streptavidin T1 beads were added and incubated at $37^{\circ} \mathrm{C}$ by end-to-end rotation overnight. The beads were then washed twice at $50^{\circ} \mathrm{C}$ by high salt wash buffer $(20 \mathrm{mM}$ Tris$\mathrm{HCl}, 500 \mathrm{mM} \mathrm{NaCl}, 1 \% \mathrm{SDS}$ ), followed by 3 washes with $0.1 \times$ SSC wash buffer (0.1× SSC, $1 \%$ SDS) at $37^{\circ} \mathrm{C}$. We allowed $15-20$ min of end-to-end rotation per wash. For DNA isolation, the beads were further washed one time with SDS elution buffer $(50 \mathrm{mM}$ Tris- $\mathrm{Cl}, 5 \mathrm{mM} \mathrm{MgCl}, 75 \mathrm{mM} \mathrm{NaCl}$, $1 \% \mathrm{SDS}$ ) at $37^{\circ} \mathrm{C}$ for $20 \mathrm{~min}$, and one time with elution buffer $(50 \mathrm{mM}$ Tris-Cl, $5 \mathrm{mM} \mathrm{MgCl}, 75 \mathrm{mM} \mathrm{NaCl}, 0.1 \%$ Triton X-100) at $39^{\circ} \mathrm{C}$ for $5 \mathrm{~min}$. Then, DNA was eluted sequentially by RNase $\mathrm{H}$ elution buffer $(50 \mathrm{mM}$ Tris-Cl, $5 \mathrm{mM} \mathrm{MgCl}, 75 \mathrm{mM} \mathrm{NaCl}, 0.1 \%$ Triton X-100, 0.5U/I RNase H) at $37^{\circ} \mathrm{C}$ for $20 \mathrm{~min}$, and by SDS elution buffer at room temperature for $2 \mathrm{~min}$. The eluents were combined. And the crosslinking was reversed in the presence of $0.1 \mu \mathrm{g} / \mu \mathrm{l}$ protease $\mathrm{K}, 150 \mathrm{mM} \mathrm{NaCl}$, and $10 \mathrm{mM}$ EDTA incubate at $50^{\circ} \mathrm{C}$. Then add $300 \mu \mathrm{PhOH}$ :Chloroform:Isoamyl per sample. Shake vigorously for $10 \mathrm{~min}$, and spin down on a benchtop centrifuge at $16,100 \times g$ for $5 \mathrm{~min}$ at $4{ }^{\circ} \mathrm{C}$. Take aqueous from the top. Add $30 \mu \mathrm{l}$ $\mathrm{NaOAc}$, and $900 \mu \mathrm{l} 100 \% \mathrm{EtOH}$. Mix well and store at $-20^{\circ} \mathrm{C}$ overnight. Spin samples at $16,100 \times g$ for $30 \mathrm{~min}$ at $4^{\circ} \mathrm{C}$. Decant supernatant carefully. Add $1 \mathrm{~mL} 70 \% \mathrm{EtOH}$ and vortex to mix. Spin at $16,100 \times g$ for $5 \mathrm{~min}$. Remove supernatant by pipette. Air dry for $1 \mathrm{~min}$. Resuspend in

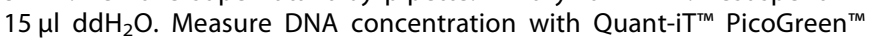
dsDNA Assay Kit (P7589) (Invitrogen, Shanghai, China). Library construction was done by using NEB library construction modules and following the instrument of NEBNext ${ }^{\circledR}$ ChIP-Seq Library Prep Reagent Set for Illumina (\#E6200S) (California, USA).

\section{Sequencing data analysis}

RNA-Seq reads were mapped using TopHat v2.0.11 software [59]. For K-R and K-S data, HT-Seq was used to calculate the gene counts [60], and then DEGSeq [61] was used to analyze the differentially expressed genes. For K-RScramble and K-R-shHOTAIRM1, FPKM (Fragments Per Kilobase per Million) values were calculated using Cufflink 2.1.1 to represent expression levels [62]. For ChIRP and DNA-Seq data, raw reads were uniquely mapped to the human genome (hg38) using Bowtie v.1.0.0 software [63]. Positive peaks were identified by MACS [43] program by comparing the wild-type and knockouttype samples with $p$-cutoff value of $1 \times 10^{-5}$. ChIP-Seq reads were aligned using Bowtie, and peaks were identified using MACS v.1.4.2 software [43].

\section{Luciferase reporter assay}

Luciferase reporter assay was performed with pGL3 vectors of Promega (Madison, Wisconsin, USA), and luminescence was detected with Dual-Glo system from Promega. HOTAIRM1 binding DNA sequences were amplified by $\mathrm{PCR}$, and dsDNAs were inserted into pGL3-promoter vector between Smal and Xhol cleavage sites, which is $1 \mathrm{~kb}$ downstream of $3^{\prime}$ end of the firefly luciferase gene. The cloned vector was co-transfected with pRL-TK renilla luciferase control reporter vectors into Kasumi-1 cells. The firefly and renilla luminescence were detected in the transfected cells after $48 \mathrm{~h}$ using Dual-Glo luciferase Assay System (Promega, Madison, Wisconsin, USA). The firefly luminescence was normalized to renilla luminescence under various conditions. Folding inductions were then calculated by normalizing to the pGL3-promoter control.

\section{Cell viability assay}

The cells in logarithmic growth phase were washed twice with PBS and detached by trypsin to make single-cell suspension. The cells were inoculated into a 96-well plate, $5 \times 10^{3}$ cells per well (six duplicated wells), and incubated in $5 \% \mathrm{CO}_{2}$ incubator for $24-72 \mathrm{~h}$ at $37^{\circ} \mathrm{C}$. After that, $20 \mu \mathrm{l}$ MTS (Promega, Madison, Wisconsin, USA) solution was added to each well. The plate was incubated in $5 \% \mathrm{CO}_{2}$ incubator at $37^{\circ} \mathrm{C}$ for another $4 \mathrm{~h}$. Subsequently, the solution was removed. DMSO $(150 \mu \mathrm{l})$ were added in the walls and shaked for $10 \mathrm{~min}$ to dissolve the crystal. The optical density (OD) value of each well at $0,24,48$, and $72 \mathrm{~h}$ was read. MTT curve graph was constructed with $\mathrm{OD}$ value as ordinate, and the interval time as abscissa. The experiment was repeated three times.

\section{Flow cytometry}

The cells were centrifuged to remove the media, and then resuspended in $100 \mu \mathrm{l}$ of Annexin V Binding Buffer (BD PharMingen, New Jersey, USA) containing $1 \mathrm{mg} / \mathrm{ml}$ propidium iodide (Sigma-Aldrich) and APC-Annexin V (BioLegend, San Diego, USA) for $15 \mathrm{~min}$. Then $400 \mu \mathrm{l}$ of Annexin V Binding 
Buffer (BD PharMingen, New Jersey, USA) was added to the samples. The fluorescence was measured using BD LSR II flow cytometer or Gallios flow cytometer (Beckman Coulter, California,USA), and then analyzed by Flow Logic software (Miltenyi Biotec, Germany).

\section{RhoA activation assay}

RhoA activity was determined using RhoA Pull-down Activation Assay Kit (BK036-S, Cytoskeleton, Denver, USA)

\section{DATA AVAILABILITY}

The raw sequence data have been deposited in the Genome Sequence Archive in BIG Data Center, Beijing Institute of Genomics (BIG), Chinse Acadamy of Science, under accession number CRA002779 and CRA002778.

\section{REFERENCES}

1. Baxter JD, Harris AW, Tomkins GM, Cohn M. Glucocorticoid receptors in lymphoma cells in culture: relationship to glucocorticoid killing activity. Science. 1971;171:189-91.

2. Brunetti M, Martelli N, Colasante A, Piantelli M, Musiani P, Aiello FB. Spontaneous and glucocorticoid-induced apoptosis in human mature T-lymphocytes. Blood. 1995;86:4199-205.

3. Planey SL, Litswack G. Glucocorticoid-induced apoptosis in lymphocytes. Biochem Biophys Res Commun. 2000;279:307-12.

4. Wyllie AH. Glucocorticoid-induced thymocyte apoptosis is associated with endogenous endonuclease activation. Nature. 1980;284:555-6.

5. Frankfurt O, Rosen ST. Mechanisms of glucocorticoid-induced apoptosis in hematologic malignancies: updates. Curr Opin Oncol. 2004;16:553-63.

6. Gaynon PS, Carrel AL. Glucocorticosteroid therapy in childhood acute lymphoblastic leukemia. Adv Exp Med Biol. 1999:457:593-605.

7. Hyman CB., Sturgeon P. Prednisone therapy of acute lymphatic leukemia in children. Cancer. 1956;9:965-70.

8. Inaba $\mathrm{H}$, Pui CH. Glucocorticoid use in acute lymphoblastic leukaemia. Lancet Oncol. 2010;11:1096-106.

9. Dordelmann M, Reiter A, Borkhardt A, Ludwig WD, Gotz N, Viehmann S, et al. Prednisone response is the strongest predictor of treatment outcome in infant acute lymphoblastic leukemia. Blood. 1999;94:1209-17.

10. Moalli PA, Rosen ST. Glucocorticoid receptors and resistance to glucocorticoids in hematologic malignancies. Leuk Lymphoma. 1994;15:363-74.

11. Walsh $C P$, Ewing $\amalg$, Cleary $J$, Vaisleib $A D$, Farrell $C H$, Wright $A G C$ et al. Development of glucocorticoid resistance over one year among mothers of children newly diagnosed with cancer. Brain Behav Immun. 2018;69:364-73.

12. Bantel H, Domschke W, Schulze-Osthoff K. Molecular mechanisms of glucocorticoid resistance. Gastroenterology. 2000;119:1178-9.

13. Barnes PJ. Mechanisms and resistance in glucocorticoid control of inflammation J Steroid Biochem Mol Biol. 2010;120:76-85.

14. Bhadri VA, Trahair TN, Lock RB. Glucocorticoid resistance in paediatric acute lymphoblastic leukaemia. J Paediatr Child Health. 2012;48:634-40.

15. Xiao H, Ding Y, Gao Y, Wang LM, Wang H, Ding L, et al. Haploinsufficiency of NR3C1 drives glucocorticoid resistance in adult acute lymphoblastic leukemia cells by down-regulating the mitochondrial apoptosis axis, and is sensitive to $\mathrm{Bcl}$ 2 blockage. Cancer Cell Int. 2019;19:218.

16. Schlossmacher G, Stevens A, White A. Glucocorticoid receptor-mediated apoptosis: mechanisms of resistance in cancer cells. J Endocrinol. 2011;211:17-25.

17. Hala M, Hartmann BL, Bock G, Geley S, Kofler R. Glucocorticoid-receptor-gene defects and resistance to glucocorticoid-induced apoptosis in human leukemic cell lines. Int J Cancer. 1996;68:663-8.

18. Bailey S, Hall AG, Pearson AD, Redfern CP. The role of AP-1 in glucocorticoid resistance in leukaemia. Leukemia. 2001;15:391-7.

19. Ploner $C$, Rainer J, Niederegger $H$, Eduardoff $M$, Villunger $A$, Geley $S$, et al. The $\mathrm{BCL} 2$ rheostat in glucocorticoid-induced apoptosis of acute lymphoblastic leukemia. Leukemia. 2008;22:370-7.

20. Cialfi S, Palermo R, Manca S, Checquolo S, Bellavia D, Pelullo M, et al. Glucocorticoid sensitivity of T-cell lymphoblastic leukemia/lymphoma is associated with glucocorticoid receptor-mediated inhibition of Notch1 expression. Leukemia. 2013;27:485-8

21. Zacharchuk CM, Mercep M, Chakraborti PK, Simons SS, Ashwell JD. Programmed lymphocyte-T death-cell activation-induced and steroid-induced pathways are mutually antagonistic. J Immunol. 1990;145:4037-45.

22. Nagao K, Iwai Y, Miyashita T. RCAN1 is an important mediator of glucocorticoidinduced apoptosis in human leukemic cells. PLoS ONE. 2012;7:e49926.
23. Xie M, Yang A, Ma J, Wu M, Xu H, Wu K, et al. Akt2 mediates glucocorticoid resistance in lymphoid malignancies through FoxO3a/Bim axis and serves as a direct target for resistance reversal. Cell Death Dis. 2019;9:1013.

24. Jing $D$, Bhadri VA, Beck D, Thoms JA, Yakob NA, Wong JW, et al. Opposing regulation of BIM and BCL2 controls glucocorticoid-induced apoptosis of pediatric acute lymphoblastic leukemia cells. Blood. 2015;125:273-83.

25. Heidari N, Miller AV, Hicks MA, Marking CB, Harada H. Glucocorticoid-mediated BIM induction and apoptosis are regulated by Runx2 and c-Jun in leukemia cells. Cell Death Dis. 2012;3:e349.

26. Du P, Hu C, Qin Y, Zhao J, Patel R, Fu Y, et al. LncRNA PVT1 mediates antiapoptosis and 5-fluorouracil resistance via increasing $\mathrm{Bcl} 2$ expression in gastric cancer. J Oncol. 2019;2019:9325407.

27. Guo F, Cao Z, Guo H, Li S. The action mechanism of IncRNA-HOTAIR on the drug resistance of non-small cell lung cancer by regulating Wnt signaling pathway. Exp Ther Med. 2018;15:4885-9.

28. Huang P, Li F, Li L, You Y, Luo S, Dong Z, et al. IncRNA profile study reveals the mRNAs and IncRNAs associated with docetaxel resistance in breast cancer cells. Sci Rep. 2018;8:17970.

29. Schneider C, King RM, Philipson L. Genes specifically expressed at growth arrest of mammalian cells. Cell. 1988:54:787-93.

30. Kino T, Hurt DE, Ichijo T, Nader N, Chrousos GP. Noncoding RNA Gas5 is a growth arrest- and starvation-associated repressor of the glucocorticoid receptor. Sci Signal. 2010;3:ra8

31. Hudson WH, Pickard MR, De Vera IM, Kuiper EG, Mourtada-Maaraboun $\mathrm{M}$, Conn $\mathrm{GL}$, et al. Conserved sequence-specific lincRNA-steroid receptor interactions drive transcriptional repression and direct cell fate. Nat Commun. 2014;5:5395

32. Lucafo M, De ludicibus S, Di Silvestre A, Pelin M, Candussio L, Martelossi S, et al. Long noncoding RNA GAS5: a novel marker involved in glucocorticoid response. Curr Mol Med. 2015;15:94-99.

33. Lanz RB, Mckenna NJ, Onate SA, Albrecht U, Wong JM, Tsai SY, et al. A steroid receptor coactivator, SRA, functions as an RNA and is present in an SRC-1 complex. Cell. 1999;97:17-27.

34. Foulds CE, Tsimelzon A, Long W, Le A, Tsai SY, Tsai MJ, et al. Research resource: expression profiling reveals unexpected targets and functions of the human steroid receptor RNA activator (SRA) gene. Mol Endocrinol. 2010;24: 1090-105.

35. Asou H, Tashiro S, Hamamoto K, Otsuji A, Kita K, Kamada N. Establishment of a human acute myeloid leukemia cell line (Kasumi-1) with 8;21 chromosome translocation. Blood. 1991;77:2031-6.

36. Diaz-Beya M, Brunet S, Nomdedeu J, Pratcorona M, Cordeiro A, Gallardo D, et al. The lincRNA HOTAIRM1, located in the HOXA genomic region, is expressed in acute myeloid leukemia, impacts prognosis in patients in the intermediate-risk cytogenetic category, and is associated with a distinctive microRNA signature. Oncotarget. 2015;6:31613-27.

37. Li Q, Dong C, Cui J, Wang Y, Hong X. Over-expressed IncRNA HOTAIRM1 promotes tumor growth and invasion through up-regulating HOXA1 and sequestering G9a/EZH2/Dnmts away from the HOXA1 gene in glioblastoma multiforme. J Exp Clin Cancer Res. 2018;37:265.

38. Xia H, Liu Y, Wang Z, Zhang W, Qi M, Qi B, et al. Long noncoding RNA HOTAIRM1 maintains tumorigenicity of glioblastoma stem-like cells through regulation of HOX gene expression. Neurotherapeutics. 2020;17:754-64.

39. Zhang $X$, Weissman SM, Newburger PE. Long intergenic non-coding RNA HOTAIRM1 regulates cell cycle progression during myeloid maturation in NB4 human promyelocytic leukemia cells. RNA Biol. 2014;11:777-87.

40. Tomczak K, Czerwinska P, Wiznerowicz M. The Cancer Genome Atlas (TCGA): an immeasurable source of knowledge. Contemp Oncol. 2015;19: A68-77.

41. Chu C, Qu K, Zhong FL, Artandi SE, Chang HY. Genomic maps of long noncoding RNA occupancy reveal principles of RNA-chromatin interactions. Mol Cell. 2011;44:667-78.

42. Chu C, Quinn J, Chang HY. Chromatin isolation by RNA purification (ChIRP). J Vis Exp. 2012;61:3912.

43. Zhang Y, Liu T, Meyer CA, Eeckhoute J, Johnson DS, Bernstein BE, et al. Modelbased analysis of ChIP-Seq (MACS). Genome Biol. 2008;9:R137.

44. Mclean CY, Bristor D, Hiller M, Clarke SL, Schaar BT, Lowe CB, et al. GREAT improves functional interpretation of cis-regulatory regions. Nat Biotechnol. 2010;28:495-501.

45. Maeda $M$, Hasegawa $H$, Hyodo $T$, Ito $S$, Asano $E$, Yuang $H$, et al. ARHGAP18, a GTPase-activating protein for RhoA, controls cell shape, spreading, and motility. Mol Biol Cell. 2011:22:3840-52.

46. Zhang X, Lian Z, Padden C, Gerstein MB, Rozowsky J, Snyder M, et al. A myelopoiesis-associated regulatory intergenic noncoding RNA transcript within the human HOXA cluster. Blood. 2009;113:2526-34. 
14

47. Consortium EP. An integrated encyclopedia of DNA elements in the human genome. Nature. 2012;489:57-74.

48. Fornes O, Castro-Mondragon JA, Khan A, Van Der Lee R, Zhang X, Richmond PA, et al. JASPAR 2020: update of the open-access database of transcription factor binding profiles. Nucleic Acids Res. 2020;48:D87-D92.

49. Kilbey A, Terry A, Wotton S, Borland G, Zhang Q, Mackay N, et al. Runx1 orchestrates sphingolipid metabolism and glucocorticoid resistance in lymphomagenesis. J Cell Biochem. 2017;118:1432-41.

50. Luo Y, He Y, Ye X, Song J, Wang Q, Li Y, et al. High expression of long noncoding RNA HOTAIRM1 is associated with the proliferation and migration in pancreatic ductal adenocarcinoma. Pathol Oncol Res. 2019;25:1567-77.

51. Wan L, Kong J, Tang J, Wu Y, Xu E, Lai M, et al. HOTAIRM1 as a potential biomarker for diagnosis of colorectal cancer functions the role in the tumour suppressor. J Cell Mol Med. 2016;20:2036-44.

52. Zhang $Y$, Mi L, Xuan Y, Gao C, Wang YH, Ming HX, et al. LncRNA HOTAIRM1 inhibits the progression of hepatocellular carcinoma by inhibiting the Wnt signaling pathway. Eur Rev Med Pharmacol Sci. 2018;22:4861-8.

53. Chu C, Zhang QC, Da Rocha ST, Flynn RA, Bharadwaj M, Calabrese JM, et al. Systematic discovery of xist RNA binding proteins. Cell. 2015;161:404-16.

54. Vance KW, Ponting CP. Transcriptional regulatory functions of nuclear long noncoding RNAs. Trends Genet. 2014;30:348-55.

55. Wang KC, Chang HY. Molecular mechanisms of long noncoding RNAs. Mol Cell. 2011;43:904-14.

56. Yang L, Froberg JE, Lee JT. Long noncoding RNAs: fresh perspectives into the RNA world. Trends Biochem Sci. 2014;39:35-43.

57. Hung $T$, Wang $Y$, Lin MF, Koegel AK, Kotake $Y$, Grant GD, et al. Extensive and coordinated transcription of noncoding RNAs within cell-cycle promoters. Nat Genet. 2011;43:621-9.

58. Wei S, Zhao M, Wang X, Li Y, Wang K. PU.1 controls the expression of long noncoding RNA HOTAIRM1 during granulocytic differentiation. J Hematol Oncol. 2016;9:44.

59. Kim D, Pertea G, Trapnell C, Pimentel H, Kelley R, Salzberg SL. TopHat2: accurate alignment of transcriptomes in the presence of insertions, deletions and gene fusions. Genome Biol. 2013;14:R36.

60. Anders S, Pyl PT, Huber W. HTSeq-a Python framework to work with highthroughput sequencing data. Bioinformatics. 2015;31:166-9.

61. Wang L, Feng Z, Wang X, Wang X, Zhang X. DEGseq: an R package for identifying differentially expressed genes from RNA-seq data. Bioinformatics. 2010;26: 136-8.

62. Trapnell C, Roberts A, Goff L, Pertea G, Kim D, Kelley DR, et al. Differential gene and transcript expression analysis of RNA-seq experiments with TopHat and Cufflinks. Nat Protoc. 2012;7:562-78.

63. Langmead B, Trapnell C, Pop M, Salzberg SL. Ultrafast and memory-efficient alignment of short DNA sequences to the human genome. Genome Biol. 2009;10: R25.

\section{ACKNOWLEDGEMENTS}

We thank Dr. Maxwell Mumbach (Stanford University) for his invaluable help and advice in establishing the ChIRP protocol.

\section{AUTHOR CONTRIBUTIONS}

SM conceived the study. SM and LL designed experiments. LL performed experiments and analyzed data. WG established the glucocorticoid-resistant cells. WG, ML, RG, XZ, and CG performed experiments. SM and LL drafted and reviewed the manuscript with contributions from other authors.

\section{FUNDING}

This work was supported by the Strategic Priority Research Program of Chinese Academy of Sciences (Grant No. XDB38030400), National basic research program of China (Grant No. 2015CB910603).

\section{COMPETING INTERESTS}

The authors declare no competing interests.

\section{ETHICS STATEMENT}

Ethics approval was not required for this research.

\section{ADDITIONAL INFORMATION}

Supplementary information The online version contains supplementary material available at https://doi.org/10.1038/s41419-021-03982-4.

Correspondence and requests for materials should be addressed to S.M.

Reprints and permission information is available at http://www.nature.com/ reprints

Publisher's note Springer Nature remains neutral with regard to jurisdictional claims in published maps and institutional affiliations.

Open Access This article is licensed under a Creative Commons By Attribution 4.0 International License, which permits use, sharing, adaptation, distribution and reproduction in any medium or format, as long as you give appropriate credit to the original author(s) and the source, provide a link to the Creative Commons license, and indicate if changes were made. The images or other third party material in this article are included in the article's Creative Commons license, unless indicated otherwise in a credit line to the material. If material is not included in the article's Creative Commons license and your intended use is not permitted by statutory regulation or exceeds the permitted use, you will need to obtain permission directly from the copyright holder. To view a copy of this license, visit http://creativecommons. org/licenses/by/4.0/.

(c) The Author(s) 2021 